\title{
The Role of Platelet Gel in Regenerative Medicine
}

\author{
Primož Rožman1, Danijela Semenič² and Dragica Maja Smrke² \\ ${ }^{1}$ Blood Transfusion Centre \\ ${ }^{2}$ Department of Surgical Infections, University Clinical Centre Ljubljana
}

Slovenia

\section{Introduction}

For decades, platelet concentrates have been a standard transfusion component for the treatment of clotting disorders. They are prepared from the whole blood within 24 hours from collection from voluntary blood donors by means of differential centrifugation of platelet rich plasma (PRP) or by the apheresis and stored at room temperature with a maximum shelf life of 7 days. They are transfused to the patients who suffer from thrombocytopenia or some other platelet disorder in order to sustain the haemostatic function. Freezing platelets is feasible but results in poor recovery, although the platelets retain their clotting functions after thawing. The use of platelets is permanently increasing, due to advanced surgical and other therapies and they are considered vital products in blood banking today (Brecher, 2005).

Apart from their clotting functions, platelets have been shown to possess some other evolutionary highly conserved biological functions, such as immune defence, tissue forming and regeneration. These properties are now clinically used by the virtue of platelet gel preparations. Technically, the clinical precursor of platelet gel has been fibrin glue that was composed of two separate solutions - fibrinogen and thrombin. When mixed together, these agents were similar to the last stages of the clotting cascade in forming a fibrin clot. Fibrinogen has been obtained from pooled allogeneic single-donor plasma units and from the autologous blood of the patients and has been usually isolated by the process of cryoprecipitation. The additional thrombin component has been generally derived from commercial bovine sources. Some investigators have even added calcium chloride and/or antifibrinolytics (i.e., aminocaproic acid, aprotinin) to their preparations in order to enhance the clot formation. Although fibrin glue has been used in a variety of surgical procedures for the prevention of bleeding, it has been especially useful in heparinized patients undergoing cardiovascular procedures requiring extracorporeal circulation, as it does not need an intact hemostatic system to be effective. Fibrin glue has also been evaluated in the presealing of woven or knitted Dacron vascular grafts. The major drawback to its use has been attributed to the potential risk of transmitted serological disease from pooled and single-donor blood donors, so the patient's own blood was considered to be the safest preparation to prepare fibrin glue. Overall, fibrin glue is a useful adjunct to other methods to control bleeding in selected surgical patients (Thompson et al., 1988; Lee \& Kang, 2011). 
Autologous platelet rich plasma, which is by the activation of platelets converted to platelet gel (PG) was developed in the early 1970s as a by-product of multicomponent apheresis. The first published paper relating to the use of platelet-fibrinogen-thrombin mixture as a "corneal adhesive" is dated from 1975 ( Rosenthal et al., 1975). In 1979, a report was published about platelet gel "gel foam" used to obtain sutureless nerve anastomosis (Fischer, 1979). Another publication in 1980, described the role of fibrin to drive fibroblast migration and collagen deposition and leading to granulation tissue formation (Brandstedt et al., 1980).

Articles published in the 1990s provided numerous insights into the basic mechanisms of the physiologic process of healing after injury had occurred. Some of the results provided by these papers were that fibroblasts are recruited at the injury site by soluble factors; that the platelet releasate contains a high level of chemotactic factors that recruit fibroblasts in a strictly dose-dependent manner, that the fibroblasts migrate along a fibrin-rich matrix; and that fibronectin is necessary for such migration to occur since it provides a conduit for transmigration. In their migration, fibroblasts adhere to the fibronectin fibres through alpha5beta 1 and alpha5beta3 receptors. Proteases are necessary for fibroblast transmigration through the fibrin-rich matrix (the role of metalloproteases was depicted some years later). Interestingly, the fibrin/ fibronectin fibres retain growth factors released from the activated platelets within the injured site (Greiling \& Clark, 1997).

In 1996, the physiological relationship between mesenchymal cells, fibrin and growth factors was shown to result in the establishment of granulation tissue. It was demonstrated that the formation of granulation tissue is strongly enhanced by the platelet releasate. The platelet releasate provides continuous stimulation for mesenchyme-derived cells to interact with fibrin, thus accelerating the development of granulation tissue (McClain et al., 1996). It is now confirmed that the human platelet lysate can induce the expansion of human mesenchymal stem cells in vitro, which will by omitting the animal derived albumin, change the cell cultivation approaches for regenerative medicine.

One of the first disciplines that readily accepted the new regenerative capacity of the PRP/PG was the maxillofacial surgery (Schallmoser et al., 2007). PRP was introduced to the maxillofacial community by Whitman et al. as an alternative to the fibrin glue in 1997 (Whitman et al., 1997). Marx et al. showed that by combining PRP with autologous bone in mandibular continuity defects resulted in significantly faster radiographic maturation and a histomorphometrically denser bone regeneration (Marx et al., 1998).

In 2000 - 2010 authors observed various healing effects of PG, for instance that chronic lower extremity ulcers (diabetic, post-traumatic, vascular) reepithelialized faster with the course of twice-daily wound treatment with platelet releasate as compared with similar wounds treated with a placebo. The supernatant or releasate of the platelet gel was able to promote dose-dependent proliferation and changes in gene expression as well as in metabolic activities related to protein synthesis (Junger et al., 2000;Valencia et al., 2001; Fang \& Galiano, 2008; Bernuzzi et al., 2010; Ficarelli et al., 2008; Chen et al., 2010). The platelet concentrate was used for healing skin, soft tissue wounds, fractures, surgical injuries, diabetic ulcers, dental, oral and maxillofacial settings (Altman et al., 2001; Margolis et al., 2001; Anderson \&Baker, 2003; Castro, 2004; Belli et al., 2005; Burkus, 2005; Carreon et al., 2005; Sclafani et al., 2005; Trowbridge et al., 2005; Brown et al., 2006; Driver et al., 2006; Savarino et al., 2006; Rozman \& Bolta, 2007; Borzini \& Mazzucco 2007; Smrke et al., 2007; Cieslik-Bielecka et al., 2008;). 
Novel strategies of platelet gel application in cardiology were under investigation in the year 2004. Studies evaluated the use of platelet gel in the case of myocardial injury, in order to promote remodelling through the regeneration of myocytes, the induction of angiogenesis and the restoration of a normal extracellular matrix composition (Mogan \& Larson, 2004; Balbo et al., 2010;).

PG/PRP was further intensively studied. Human umbilical vein endothelial cells (HUVECs) were isolated from umbilical cord veins and grown in appropriate conditions in vitro. The platelet gel-released supernatant was able to induce proliferation and to stimulate motility and the invasiveness of HUVECs. Higher concentrations of PG induced a reversion of the stimulatory processes. It became clear that different concentrations of the platelet growth factors do not have the same efficacy in inducing these processes: excessively high concentrations can have an inhibitory effect on the processes. Further studies are necessary to reach a better understanding of these complex biological processes (Rughetti et al., 2008). PG treatment in 2008 revealed a unique capacity of articulating a pro-inflammatory and proangiogenic cytokine profile in human peripheral blood mononuclear cells, co-cultured with PG, which may partially explain the clinical success of PG application in a wide range of diseases (Naldini et al., 2008).

A 1-year retrospective review of a cardiac surgery patient in 2008 showed that the treatment group with PG significantly shortened the duration of intensive care and decreased the total length of stays as well as decreased postoperative blood loss, compared with the control group. In addition, the treatment group had no reported incisional wound infections (Englert et al., 2008; Gunaydin et al., 2008).

\section{Platelet structure and physiology}

Platelets are not "real" cells but rather non-nuclear cellular fragments derived from the megakaryocytes in the bone marrow through controlled cellular fragmentation, followed by their release into circulation (Jurk \& Kehrel, 2005). A healthy adult aged between 30 and 70, weighing $70 \mathrm{~kg}$, has in total about 1,300-1,500 grams of platelets (thrombocytes); $40 \%$ of them in the spinal bone marrow, $25 \%$ in the ribs and sternum, $15 \%$ in the pelvis, $10 \%$ in the skull, and $10 \%$ in other bones. Progenitor cells of the thrombocytic lineage develop in the same way as other immature cells of bloodlines in the bone marrow, originating from the common hematopoietic stem cell. When immature cells differentiate into directed stem cells they are morphologically recognizable as the progenitor cells of thrombocytic lineage. The progenitor cell is the megakaryoblast, with 21-50 mm diameter, which develops from the common myeloid progenitor named CFU-GEMM. The megakaryoblast gives rise to the promegakaryocyte and then the megakaryocyte - the largest cell in the bone marrow with $70-100 \mathrm{~mm}$ in diameter. Several growth factors are involved in the platelet differentiation, among which the thrombopoietin plays the most decisive role, inducing thrombopoiesis in a negative loop fashion by binding to the thrombocytes when they are present in sufficient numbers, thus decreasing their production from the HSCs in the bone marrow (See Figure 1).

There are 1/3 immature and 2/3 mature elements of megakaryocyte lineage in the bone marrow. Thrombocytes are formed by the breaking off of small fragments of the 
megakaryocyte cytoplasm. Each megakaryocyte gives rise to 2,000 to 4,000 thrombocytes. The development of the megakaryocyte from the megakaryoblast takes $4-5$ days, and the life-span of a thrombocyte is 7-10 days. The number of thrombocytes in the peripheral blood is 150-350 $\times 10 \mathrm{E} 9 / \mathrm{L}$. If functionally classified, platelets consist of various molecules: membrane proteins $3 \%$, signalling proteins $24 \%$, cytoskeletal $15 \%$, vesicular $6 \%$, extracellular $4 \%$, mitochondrial $7 \%$, protein processing $22 \%$, metabolic enzymes $6 \%$, unknown 4\%, miscellaneous 5.5\% and nuclear proteins 3.5\% (Garcia et al., 2004).

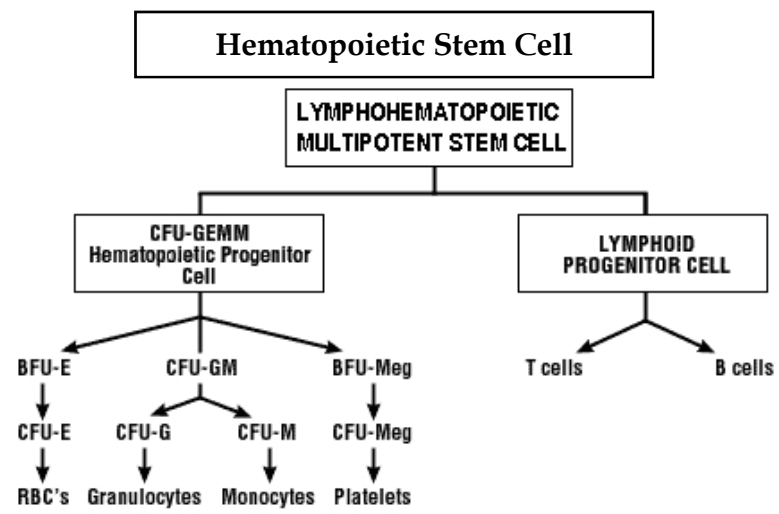

Fig. 1. Thrombopoiesis in the bone marrow

As mentioned previously, platelets are primarily specialized secretory cells that release the contents of their intracellular granules in response to activation. Beside their well known function in haemostasis where they prevent blood loss at the sites of vascular injury, they also release substances that promote tissue repair and influence the reactivity of vascular and blood cells in angiogenesis and inflammation (Jurk \& Kehrel, 2005). At the site of the injury, platelets release an arsenal of potent inflammatory and mitogenic substances which are involved in all aspects of the wound healing process. Based on these facts, platelet releasate in the form of activated platelet gel has been extensively used for the topical in loco therapy of various clinical conditions (Borzini \& Mazzucco, 2007). The purpose of this chapter is to review the current laboratory and clinical findings related to the therapy of these diseases with the use of platelet gel derived growth factors.

\section{Platelet activation}

Platelets are normally circulating in the blood in their resting form (Gresele at al., 2002). Non-activated platelets contain a complete array of presynthesized protein molecules important for platelet function, among which the high presence of cytoskeletal proteins, signalling proteins, membrane proteins, protein processing proteins and cytoskeleton regulatory proteins is noted (Garcia et al., 2004; Anitua et al., 2004). These molecules are synthesized already in the megakaryocytes and packaged into the granules. Three major storage compartments in platelets are alpha granules, dense granules and lyzosomes. The majority of the substances are contained in alpha granules (Rendu \& Brohard-Bohn, 2001). (See Tab. 1). 


\begin{tabular}{|c|c|c|}
\hline Category & Term & Biological activities \\
\hline Adhesive proteins & $\begin{array}{l}\text { VWf + propeptide, Fg, Fn,Vn,TSP-1, } \\
\text { laminin-8 }\end{array}$ & $\begin{array}{l}\text { Cell contact interactions, } \\
\text { clotting, extracellular matrix } \\
\text { composition }\end{array}$ \\
\hline $\begin{array}{l}\text { Clotting factors } \\
\text { and associated } \\
\text { proteins }\end{array}$ & $\begin{array}{l}\text { Factor } \mathrm{V} / \mathrm{Va} \text {, factor } \mathrm{XI} \text {, multimerin, } \\
\text { gas6, protein } \mathrm{S} \text {, high-molecular weight } \\
\text { chininogen, antithrombin, tissue factor } \\
\text { pathway inhibitor (TFPI) }\end{array}$ & $\begin{array}{l}\text { Thrombin production and its } \\
\text { regulation, angiogenesis }\end{array}$ \\
\hline $\begin{array}{l}\text { Fibrinolytic factors } \\
\text { and associated } \\
\text { proteins }\end{array}$ & $\begin{array}{l}\text { Plasminogen, PAI-I, u-PA, osteonectin, } \\
\text { a2-antiplasmin, histidine rich } \\
\text { glycoprotein, TAFI, a2-macroglobulin }\end{array}$ & $\begin{array}{l}\text { Plasmin production and } \\
\text { vascular remodelling }\end{array}$ \\
\hline $\begin{array}{l}\text { Proteases and anti- } \\
\text { proteases }\end{array}$ & $\begin{array}{l}\text { Tissue inhibitor of metalloprotease-4 } \\
\text { (TIMP-4), matrix metalloproteinases } \\
\text { MMP-1,-2,-3, -4, -9, platelet inhibitor of } \\
\text { FIX, protease nexin-2, C1 inhibitor, a1- } \\
\text { antitripsin }\end{array}$ & $\begin{array}{l}\text { Potentiation of aggregation, } \\
\text { angiogenesis, vascular } \\
\text { modelling, regulation of } \\
\text { coagulation, regulation of } \\
\text { cellular behaviour }\end{array}$ \\
\hline $\begin{array}{l}\text { Growth factors, } \\
\text { cytokines and } \\
\text { chemokines }\end{array}$ & $\begin{array}{l}\text { PDGF, TGF } \beta 1 \text { and } 2, \text { EGF, IGF-1, VEGF } \\
\text { (A and C), bFGF and FGF-2, hepatocyte } \\
\text { GF, RANTES, IL-8, MIP-1 } \alpha \text {, growth } \\
\text { regulated oncogene- } \alpha \text {, ENA-78, MCP-3, } \\
\text { angiopoietin-1, Il-1 } \beta \text {, IGF BP-3, } \\
\text { neutrophile chemo active protein }\end{array}$ & $\begin{array}{l}\text { Chemotaxis, cell } \\
\text { proliferation and } \\
\text { differentiation, angiogenesis }\end{array}$ \\
\hline $\begin{array}{l}\text { Basic proteins and } \\
\text { others }\end{array}$ & $\begin{array}{l}\text { PF4, } \beta \text {-thromboglobulin, platelet basic } \\
\text { protein, connective tissue activating } \\
\text { peptide III, neutrophile activating } \\
\text { peptide- } 2 \text {, endostatins }\end{array}$ & $\begin{array}{l}\text { Regulation of angiogenesis, } \\
\text { vascular modelling, cellular } \\
\text { interactions. Endostatin is an } \\
\text { endogenous inhibitor of } \\
\text { angiogenesis and the growth } \\
\text { of both primary tumors and } \\
\text { metastasis. }\end{array}$ \\
\hline $\begin{array}{l}\text { Anti-microbial } \\
\text { proteins }\end{array}$ & Thrombocidins & $\begin{array}{l}\text { Bactericidal and fungicidal } \\
\text { properties }\end{array}$ \\
\hline Others & $\begin{array}{l}\text {-chondroitin 4-sulfate, albumin, } \\
\text { immunoglobulins }\end{array}$ & Diverse \\
\hline $\begin{array}{l}\text { Membrane } \\
\text { glycoproteins }\end{array}$ & $\begin{array}{l}\text { aIIb } \beta 3, \text { a } \beta 3, \text { GPIb, PECAM- } 1 \text {, most } \\
\text { plasma membrane constituents, } \\
\text { receptors for primary agonists, CD40L, } \\
\text { tissue factor, P-selectin }\end{array}$ & $\begin{array}{l}\text { Platelet aggregation and } \\
\text { adhesion, endocytosis of } \\
\text { proteins, inflammation, } \\
\text { thrombin generation, } \\
\text { platelet-leukocyte } \\
\text { interactions }\end{array}$ \\
\hline
\end{tabular}

Table 1. The contents of the platelet alpha-granules

When adhered to exposed endothelium or activated by agonists, platelet change their shape and secrete the contents of the granules (including ADP, fibrinogen and serotonin), which is followed by the platelet aggregation. The initiation of the signalling event within the platelet leads to the reorganization of the platelet cytoskeleton, which is seen as an extremely rapid shape change (See Figure 2). 

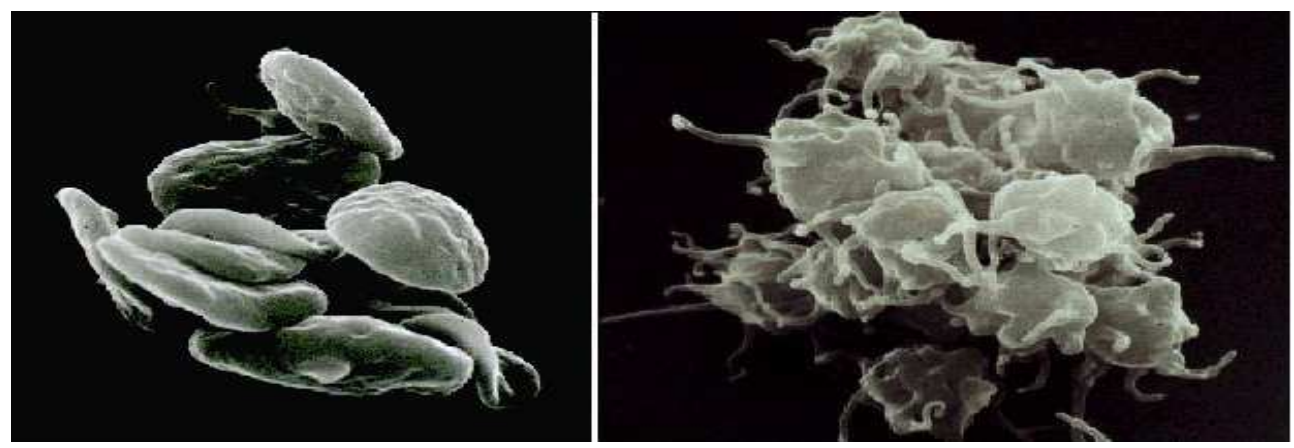

Legend: Resting platelets are smooth and disc shaped (left). Activated platelets have an irregular shape with many protruding pseudopodia (right).

Fig. 2. Platelets in their resting form and at the beginning of the activation.

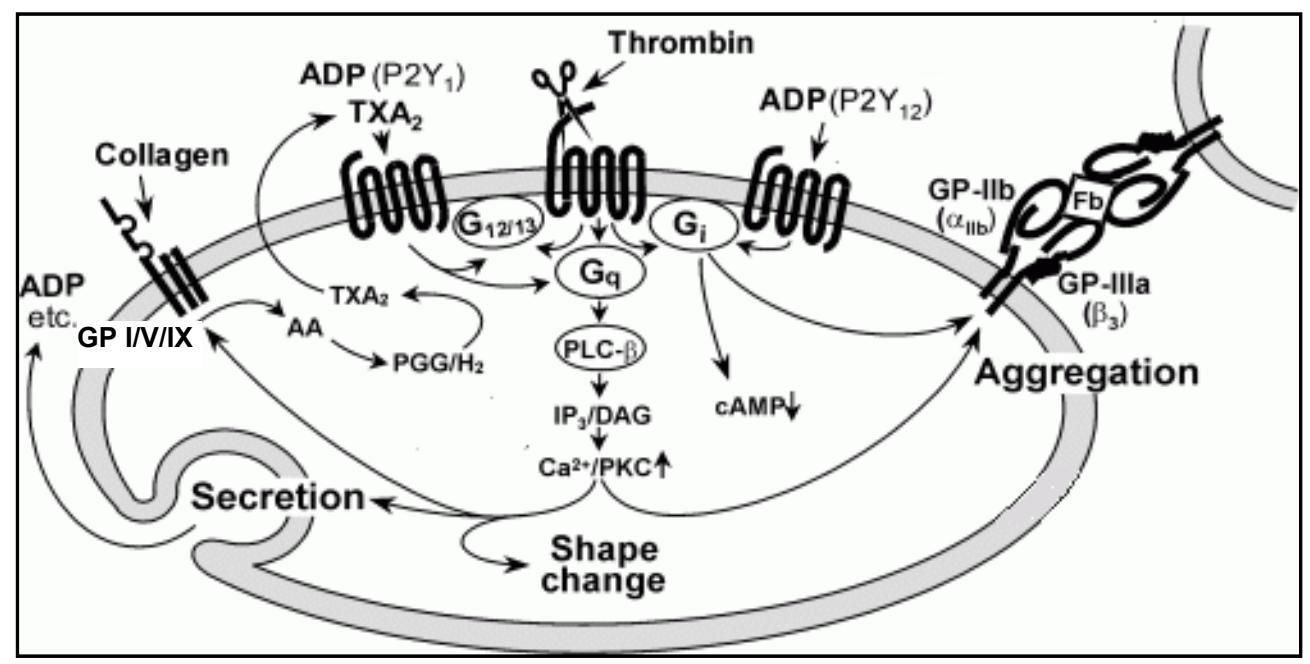

Fig. 3. Schematic representation of intracellular events during platelet activation - "outside in" and "inside out" signalling

Initiation of the signalling event within the platelet leads to the reorganization of the platelet cytoskeleton, which is seen as an shape change. Aggregation of platelets is mediated by molecules of fibrinogen or vWf, which connect platelets by bridging complexes of glycoprotein $\mathrm{IIb} / \mathrm{III}$ (integrin $\mathrm{a}_{\mathrm{II}} \beta_{3}$ ) on adjacent platelets, forming a platelet aggregate. In order to bind the fibrinogen and vWf, GP-IIb/IIIa initially has to be converted from a low affinity/avidity state to a high affinity/avidity state by a process described as "inside-out signalling" that is initiated during and after platelet activation. Some of the substances 
released by these cells - in particular adenosine diphosphate, serotonin, thromboxane and others - can, in an autocrine and paracrine fashion, further enhance platelet activation and aggregation (See Figure 3.). Under these conditions there is also activation of the coagulation cascade; therefore thrombin is formed, which also markedly stimulates the platelet activation in a positive feedback loop fashion (Gresele et al., 2002).

\section{Platelet receptors and antigens}

It has been proposed that the original function of the mammalian platelets resembled the function of primitive haemocytes in certain lower organisms such as caterpillars, in which they mostly act as a defence against foreign organisms by adhering and aggregating to foreign bodies. This is probably the reason why human platelets also possess many features of classical inflammatory cells. As such, they can undergo chemotaxis, release potent inflammatory mediators such as platelet factor PF4 and histamine, they can phagocytose foreign particles, interact with neutrophils, stimulate basophiles, excrete a number of mediators, cytokines, growth factors and other proteins and even interact with bacteria and parasites. Platelet membranes also bear some immune molecules, such as MHC Class I molecules, Fc receptors and complement binding molecules. The platelet membrane also incorporates $\mathrm{AB} 0$ and some other polysaccharide blood group Antigens, which are very important in blood transfusion (Rožman, 2002).

The membrane of the resting platelet can modify considerably after the activation following adhesion. This stimulus causes numerous intracellular molecules that are a part of the lyzosomes, granules and other cellular compartments, to appear on the platelet surface. These molecules are therefore considered as markers of platelet activation. A short description of more than 45 distinctive platelet membrane structures found on resting platelets is given in Table 2. They are usually divided into five groups: adhesion molecules, immune molecules, receptors, blood group antigens and some other molecules.

An extensive review of all molecules found on platelets and their precursors is given in references (Kishimoto et al., 1997). The CD designations of all integral molecules of the platelet membrane, as agreed upon at the 9th HLDA (Human Leukocyte Differentiation Antigens) workshop in 2010., can also be found on the internet addresses: $h t t p: / / h c d m . o r g$.

Many antigenic systems that are typical for erythrocytes and leukocytes, are also present on platelet membranes, including ABO and HLA antigens. Some others are exclusively found on platelets and their precursors. They are called human platelet alloantigens (HPA) and located on the platelet glycoproteins GPIa/IIa, GPIIb/IIIa and GPI/V/IX as a polymorphic part of the aminoacid chain. These polymorphisms are usually caused by a single nucleotide and the consequent aminoacid substitutions. The polymorphisms that cause alloimmunisation following transfusion and pregnancy were classified into the immunogenetic system of HPA (human platelet alloantigens) (Santoso \& Kiefel, 1998). (see Table 3. and EMBL EBI immune polymorphysm database at the http://www.ebi.ac.uk).

For transfusion and transplantation, AB0, HPA and HLA antigens are important due to their capability of inducing an immune response in antigen- negative recipients. This could play a role in the allogeneic platelet gel settings, but surprisingly we could not find any immune consequences of the allogeneic platelet gel use in observed patients, treated topically with allogeneic platelets, as will be discussed later. 


\begin{tabular}{|c|c|c|c|}
\hline Group & SUBGROUP & Members & Characteristics and function \\
\hline \multirow{18}{*}{ 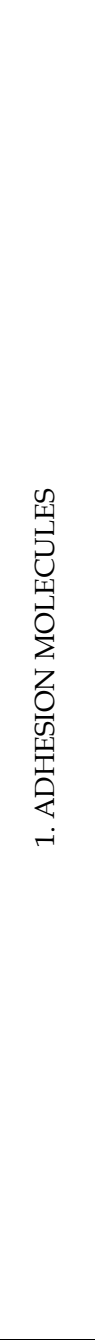 } & \multirow{8}{*}{ Integrins } & $\begin{array}{l}\text { CD41 (Integrin aIIb } \\
\text { subunit, GPIIb) }\end{array}$ & $\begin{array}{l}\text { Associates with GPIIIa into GPIIb/IIIa complex. } \\
\text { The complex binds fibrinogen, vWf, fibronectin, } \\
\text { vitronectin, thrombospondin }\end{array}$ \\
\hline & & $\begin{array}{l}\text { CD61 (Integrin } \beta 3 \\
\text { subunit) }\end{array}$ & $\begin{array}{l}\text { GPIIIa; associates with CD41 (into the GPIIb) or } \\
\text { CD51 (into the vitronectin receptor) }\end{array}$ \\
\hline & & $\begin{array}{l}\text { CD49a (Integrin a1 } \\
\text { subunit) }\end{array}$ & $\begin{array}{l}\text { Associates with CD29 ( } \beta 1 \text { subunit) into VLA-1 } \\
\text { (GPIIa), binds to collagen and laminin }\end{array}$ \\
\hline & & $\begin{array}{l}\text { CD49b (integrin a2 } \\
\text { subunit) }\end{array}$ & $\begin{array}{l}\text { GPIa or VLA-2a, associates with CD29 (GPIIa), } \\
\text { binds collagen, laminin, }\end{array}$ \\
\hline & & \begin{tabular}{|l|}
$\begin{array}{l}\text { CD49e (integrin a5 } \\
\text { subunit) }\end{array}$ \\
\end{tabular} & $\begin{array}{l}\text { a subunit of VLA-5 (vitronectin receptor), GPIc' } \\
\text { subunit, of GPIc'/IIa, binds fibronectin }\end{array}$ \\
\hline & & $\begin{array}{l}\text { CD49f (integrin a6 } \\
\text { subunit) }\end{array}$ & $\begin{array}{l}\text { VLA-6a subunit, GPIc, associates with CD29 ( } \beta 1) \\
\text { into VLA-6 (CD49f/CD29), binds laminin }\end{array}$ \\
\hline & & \begin{tabular}{|l|} 
CD29 (integrin $\beta 1$ \\
subunit)
\end{tabular} & $\begin{array}{l}\text { Associates with CD49a in VLA-1 integrin (GPIIa) } \\
\text { on platelets }\end{array}$ \\
\hline & & $\begin{array}{l}\text { CD51 (integrin } a \mathrm{~V} \\
\text { subunit) }\end{array}$ & $\begin{array}{l}\text { Associates with CD61 into the vitronectin } \\
\text { receptor. A receptor for RGD-containing proteins } \\
\text { (fibrinogen, vWf, fibronectin, laminin, } \\
\text { thrombospondin). }\end{array}$ \\
\hline & Selectins & CD62 (P-selectin) & $\begin{array}{l}\text { Binds sialyl Lewis }{ }^{x} \text {, mediates the interaction of } \\
\text { platelets with neutrophils, monocytes and a } \\
\text { rolling interaction of neutrophils on } \\
\text { endothelium }\end{array}$ \\
\hline & \multirow{4}{*}{$\begin{array}{l}\text { Leucine-rich } \\
\text { proteins } \\
\text { (GPIb-IX-V } \\
\text { complex) }\end{array}$} & CD42ba (GPIba) & $\begin{array}{l}\text { Binds to the von Willebrand factor, receptor for } \\
\text { thrombin }\end{array}$ \\
\hline & & $\begin{array}{l}\text { CD42b } \beta(C D 42 c) \\
(\text { GPIb } \beta)\end{array}$ & \multirow{3}{*}{$\begin{array}{l}\text { Subunits of the GPIb-IX-V complex, bind to the } \\
\text { von Willebrand factor }\end{array}$} \\
\hline & & CD42d (GPV) & \\
\hline & & CD42a (GPIX) & \\
\hline & \multirow{2}{*}{$\begin{array}{l}\text { Ig - } \\
\text { superfamily }\end{array}$} & CD54 (ICAM-1) & $\begin{array}{l}\text { Interactions with integrins, receptor for } \\
\text { rhinovirus }\end{array}$ \\
\hline & & CD31 (PECAM-1) & $\begin{array}{l}\text { Interactions with integrins, inhibiting } \\
\text { neutrophile migration }\end{array}$ \\
\hline & CD44 variants & CD44 isoforms & Adhesion to the extracellular matrix \\
\hline & \multirow{2}{*}{$\begin{array}{l}\text { TM4 } \\
\text { superfamily }\end{array}$} & CD9 & $\begin{array}{l}\text { Tetra spanning membrane protein, regulation of } \\
\text { integrin function }\end{array}$ \\
\hline & & $\begin{array}{l}\text { CD165 (AD2, gp37, } \\
\text { A108) }\end{array}$ & $\begin{array}{l}\text { Adhesion molecule, thymocytes/ thymic } \\
\text { epithelium }\end{array}$ \\
\hline \multirow{7}{*}{ 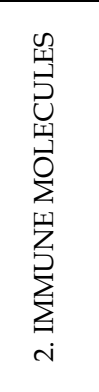 } & MHC class I. & HLA-A, B, C & Immune recognition \\
\hline & Fc receptors & CD32 (FcrRII) & $\begin{array}{l}\text { Low affinity } F_{c} \text { receptor for aggregated } \\
\text { Ig/immune complexes; activation }\end{array}$ \\
\hline & C receptors & C1q-, C2-, C4-receptors & Complement receptors \\
\hline & \multirow{4}{*}{$\begin{array}{l}\text { Regulation of } \\
\text { complement } \\
\text { activation }\end{array}$} & $\begin{array}{l}\text { CD55 - DAF (decay acc. } \\
\text { factor) }\end{array}$ & \multirow{4}{*}{$\begin{array}{l}\text { Blocking and deactivating components of } \\
\text { complement and inhibition of lysis }\end{array}$} \\
\hline & & \begin{tabular}{|l|} 
CD59 - MIRL \\
\end{tabular} & \\
\hline & & $\begin{array}{l}\text { C8bp (C8-binding } \\
\text { protein) }\end{array}$ & \\
\hline & & $\begin{array}{l}\text { CD46 - MCP (membr. } \\
\text { cof. prot.) }\end{array}$ & \\
\hline
\end{tabular}




\begin{tabular}{|c|c|c|c|}
\hline \multirow{17}{*}{ 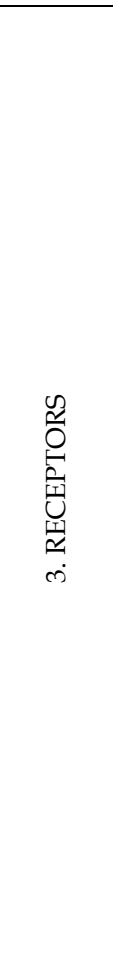 } & \multirow{9}{*}{$\begin{array}{l}\text { Receptors for } \\
\text { primary } \\
\text { agonists }\end{array}$} & $\begin{array}{l}\text { Medium affinity } \\
\text { thrombin rec. }\end{array}$ & \multirow{9}{*}{$\begin{array}{l}\text { Mediate activation by agonistic ligands through } \\
\text { different mechanisms }\end{array}$} \\
\hline & & $\begin{array}{l}\text { High affinity thrombin } \\
\text { rec. }\end{array}$ & \\
\hline & & Epinephrine receptor & \\
\hline & & $\begin{array}{l}\text { TX A2 - thromboxane } \\
\text { receptor }\end{array}$ & \\
\hline & & PAF receptor & \\
\hline & & ADP receptor & \\
\hline & & PAF receptor & \\
\hline & & Serotonin receptor & \\
\hline & & Vasopressin receptor & \\
\hline & & $\beta 2$ adrenoreceptor & \\
\hline & & Adenosine receptor & \\
\hline & $\begin{array}{l}\text { Inhibitory } \\
\text { receptors }\end{array}$ & $\begin{array}{l}\text { Prostaglandin D2 } \\
\text { (PGD2) rec. }\end{array}$ & Inhibit platelet activation \\
\hline & & $\begin{array}{l}\text { Prostaglandin I2 (PGI2) } \\
\text { rec. }\end{array}$ & \\
\hline & $\begin{array}{l}\text { Multipurpose } \\
\text { receptors }\end{array}$ & CD36 (GPIV) & $\begin{array}{l}\text { Adhesion receptor for collagen and } \\
\text { thrombospondin, receptor for } \\
\text { Plasmodium falciparum, macrophage } \\
\text { scavenger receptor }\end{array}$ \\
\hline & & CD151 (PETA-3) & Activates platelets upon stimulation with MAbs \\
\hline & $\begin{array}{l}\text { Other } \\
\text { receptors }\end{array}$ & CD110 (TPO R, MPL) & $\begin{array}{l}\text { Thrombopoietin receptor, } \\
\text { megakaryocyte proliferation and } \\
\text { differentiation }\end{array}$ \\
\hline & & CD23 (FceRII) & C-type lectin, low affinity receptor for IgE \\
\hline 00 & $\mathrm{AB} 0$ & $\mathrm{~A}, \mathrm{~B}, \mathrm{H}$ & \\
\hline ○占䎡 & Le & $\mathrm{Le}^{\mathrm{a}}, \mathrm{Le}^{\mathrm{b}}$ & \\
\hline$\stackrel{0}{0}$ & Ii & $\mathrm{I}, \mathrm{i}$ & Oligosaccharides \\
\hline 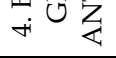 & $\mathrm{P}$ & $\mathrm{P}$ & \\
\hline & $\begin{array}{l}\text { Constitutive } \\
\text { glycosphyngol } \\
\text { ipid }\end{array}$ & $\begin{array}{l}\text { CDw17 (lactosyl } \\
\text { ceramide) }\end{array}$ & Activation, release of granules \\
\hline & $\begin{array}{l}\text { Oligosacchari } \\
\text { des }\end{array}$ & CD60 & Oligosaccharide, present on gangliosides \\
\hline 岳 & $\begin{array}{l}\text { a-granules } \\
\text { proteins }\end{array}$ & GMP-33 & Translocated to the cell surface after activation \\
\hline 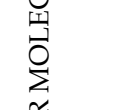 & $\begin{array}{l}\text { Lyzosomes } \\
\text { proteins }\end{array}$ & $\begin{array}{l}\text { CD107a,b (Lyzosomes- } \\
\text { associated membrane } \\
\text { proteins LAMP-1\&2) }\end{array}$ & $\begin{array}{l}\text { Liposomal membrane protein translocated to the } \\
\text { cell surface after activation }\end{array}$ \\
\hline 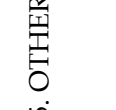 & $\begin{array}{l}\text { TM4 } \\
\text { superfamily - }\end{array}$ & $\begin{array}{l}\text { CD63 (Granulophysin, } \\
\text { LIMP) }\end{array}$ & $\begin{array}{l}\text { Tetra spanning membrane protein, liposomal } \\
\text { membrane protein translocated to the cell surface } \\
\text { after activation }\end{array}$ \\
\hline 10 & $\begin{array}{l}\text { other } \\
\text { members }\end{array}$ & CD82 & $\begin{array}{l}\text { Tetra spanning membrane protein, suppresses } \\
\text { metastasis, transduce signals in B, T cells and } \\
\text { monocytes }\end{array}$ \\
\hline & $\begin{array}{l}\text { GPI-linked } \\
\text { proteins }\end{array}$ & CD109 & $\begin{array}{l}\text { Platelet activation factor, GR56, } \\
\text { Gov }^{\mathrm{a} / \mathrm{b}} \text { alloantigen on platelets }\end{array}$ \\
\hline
\end{tabular}

Table 2. Molecules on the non-activated platelet membrane 


\begin{tabular}{|c|c|c|c|c|c|c|}
\hline System & Antigen & $\begin{array}{l}\text { Phenotype } \\
\text { frequency* }\end{array}$ & Glycoprotein & $\begin{array}{l}\text { Nucleotide } \\
\text { Change* }^{*}\end{array}$ & $\begin{array}{c}\text { Aminoacid } \\
\text { change }\end{array}$ & CD \\
\hline HPA-1 & $\begin{array}{l}\text { HPA-1a } \\
\text { HPA-1b }\end{array}$ & \begin{tabular}{l|}
$97.9 \%$ \\
$28.8 \%$ \\
\end{tabular} & GPIIIa & $\begin{array}{l}\mathrm{T}^{176} \\
\mathrm{C}^{176}\end{array}$ & \begin{tabular}{|l|} 
Leucine ${ }^{33}$ \\
Proline $^{33}$
\end{tabular} & CD61 \\
\hline HPA-2 & $\begin{array}{l}\text { HPA-2a } \\
\text { HPA-2b }\end{array}$ & $\begin{array}{l}>99.9 \% \\
13.2 \%\end{array}$ & GPIba & $\begin{array}{l}\mathrm{C}^{482} \\
\mathrm{~T}^{482}\end{array}$ & \begin{tabular}{|l} 
Threonine ${ }^{145}$ \\
Methionine
\end{tabular} & $\mathrm{CD} 42 \mathrm{~b}$ \\
\hline HPA-3 & $\begin{array}{l}\text { HPA-3a } \\
\text { HPA-3b }\end{array}$ & $\begin{array}{l}80.95 \% \\
69.8 \% \\
\end{array}$ & GPIIb & $\begin{array}{l}\mathrm{T}^{2621} \\
\mathrm{G}^{2621} \\
\end{array}$ & $\begin{array}{l}\text { Isoleucine } 843 \\
\text { Serine }^{843}\end{array}$ & CD41 \\
\hline HPA-4 & $\begin{array}{l}\text { HPA-4a } \\
\text { HPA-4b }\end{array}$ & $\begin{array}{l}>99.9 \% \\
<0.1 \% \\
\end{array}$ & GPIIIa & $\begin{array}{l}G^{506} \\
A^{506}\end{array}$ & \begin{tabular}{|l|} 
Arginine \\
Glutamine $^{143}$ \\
\end{tabular} & CD61 \\
\hline \multirow[t]{10}{*}{ HPA-5 } & $\begin{array}{l}\text { HPA-5a } \\
\text { HPA-5b }\end{array}$ & $\begin{array}{l}99.0 \% \\
19.7 \% \\
\end{array}$ & GPIa & $\begin{array}{l}\mathrm{G}^{1600} \\
\mathrm{~A}^{1600} \\
\end{array}$ & $\begin{array}{l}\text { Glutamic acid } 505 \\
\text { Lysine } 505\end{array}$ & $\mathrm{CD} 49 \mathrm{~b}$ \\
\hline & HPA-6bw & $0.7 \%$ & GPIIIa & $\begin{array}{l}\mathrm{G}^{1544} \\
\mathrm{~A}^{1544} \\
\end{array}$ & \begin{tabular}{|l|} 
Arginine \\
Glutamine 489 \\
\end{tabular} & CD61 \\
\hline & HPA-7bw & $0.2 \%$ & GPIIIa & $\begin{array}{l}C^{1297} \\
G^{1297} \\
\end{array}$ & \begin{tabular}{|l|} 
Proline 407 \\
Alanine \\
\end{tabular} & CD61 \\
\hline & HPA-8bw & $<0.01 \%$ & GPIIIa & $\begin{array}{l}\mathrm{C}^{1984} \\
\mathrm{~T}^{1984}\end{array}$ & $\begin{array}{l}\text { Arginine }^{636} \\
\text { Cysteine }^{636}\end{array}$ & CD61 \\
\hline & HPA-9bw & $0.6 \%$ & GPIIb & $\begin{array}{l}\mathrm{G}^{2602} \\
\mathrm{~A}^{2602}\end{array}$ & $\begin{array}{l}\text { Valine }{ }^{837} \\
\text { Methionine } \\
\end{array}$ & CD41 \\
\hline & HPA10bw & $<1.6 \%$ & GPIIIa & $\begin{array}{l}G^{263} \\
A^{263}\end{array}$ & $\begin{array}{l}\text { Arginine }{ }^{62} \\
\text { Glutamine }^{62} \\
\end{array}$ & CD61 \\
\hline & HPA11bw & $<0.25 \%$ & GPIIIa & $\begin{array}{l}\mathrm{G}^{1976} \\
\mathrm{~A}^{1976} \\
\end{array}$ & $\begin{array}{l}\text { Arginine } 633 \\
\text { Histidine }^{633}\end{array}$ & CD61 \\
\hline & HPA-12bw & $0.4 \%$ & GPIb $\beta$ & $\begin{array}{l}\mathrm{G}^{119} \\
\mathrm{~A}^{119} \\
\end{array}$ & $\begin{array}{l}\text { Glycine }^{15} \\
\text { Glutamic acid }^{15} \\
\end{array}$ & $\mathrm{CD} 42 \mathrm{c}$ \\
\hline & HPA-13bw & $0.25 \%$ & GPIa & $\begin{array}{l}\mathrm{C}^{2483} \\
\mathrm{~T}^{2483}\end{array}$ & $\begin{array}{l}\text { Threonine }{ }^{799} \\
\text { Methionine }{ }^{799}\end{array}$ & $\mathrm{CD} 49 \mathrm{~b}$ \\
\hline & HPA-14bw & $<0.17 \%$ & GPIIIa & $\begin{array}{c}\text { AAG1909-1911 } \\
\text { deletion }\end{array}$ & \begin{tabular}{|l|l} 
Lysine & 611 \\
deletion
\end{tabular} & CD61 \\
\hline \multirow[t]{7}{*}{ HPA-15 } & $\begin{array}{l}\text { HPA-15a } \\
\text { HPA-15b }\end{array}$ & $\begin{array}{l}81 \% \\
74 \% \\
\end{array}$ & CD109 & $\begin{array}{l}\mathrm{C}^{2108} \\
\mathrm{~A}^{2108} \\
\end{array}$ & \begin{tabular}{|l} 
Serine \\
Tyrosine \\
Ty03
\end{tabular} & CD109 \\
\hline & HPA-16bw & $<0.1 \%$ & GPIIIa & $\begin{array}{l}\mathrm{C}_{497} \\
\mathrm{~T}^{497}\end{array}$ & $\begin{array}{l}\text { Threonine } \\
\text { Istoleucine } \\
\text { Ist }\end{array}$ & CD61 \\
\hline & HPA-17bw & $<0.1 \%$ & GPIIb/IIIa & $\begin{array}{l}\mathrm{C}^{662} \\
\mathrm{~T}^{662} \\
\end{array}$ & \begin{tabular}{|l|l|} 
Threonine & 195 \\
Methionine & 195 \\
\end{tabular} & CD61 \\
\hline & HPA-18bw & $<0.1 \%$ & GPIa & $\begin{array}{l}\mathrm{G}^{2235} \\
\mathrm{~T}^{2235} \\
\end{array}$ & \begin{tabular}{|l}
$\begin{array}{l}\text { Glutamine } \\
\text { Histidine }\end{array}{ }^{716}$ \\
\end{tabular} & $\mathrm{CD} 49 \mathrm{~b}$ \\
\hline & HPA-19bw & $<0.1 \%$ & GPIIIa & $\begin{array}{l}\mathrm{A}^{487} \\
\mathrm{C}^{487} \\
\end{array}$ & \begin{tabular}{|l|} 
Lysine $^{137}$ \\
Glutamine ${ }^{137}$ \\
\end{tabular} & CD61 \\
\hline & HPA-20bw & $<0.1 \%$ & GPIIb & $\begin{array}{l}\mathrm{C}^{1949} \\
\mathrm{~T}^{1949}\end{array}$ & $\begin{array}{l}\text { Threonine }{ }^{619} \\
\text { Methionine } \\
619\end{array}$ & CD41 \\
\hline & HPA-21bw & $<0.1 \%$ & GPIIIa & $\begin{array}{l}\mathrm{G}^{1960} \\
\mathrm{~A}^{1960} \\
\end{array}$ & $\begin{array}{l}\text { Glutamic acid } 628 \\
\text { Lysine } 628\end{array}$ & CD61 \\
\hline
\end{tabular}

*Nucleotide change - numbers are given in relation to the reference sequence in the NCBI database

Table 3. Human platelet alloantigens (HPA) (Modified from Metcalfe et al. 2003 and IPD HPA database http://www.ebi.ac.uk/ipd/hpa/freqs_1.html 


\section{Platelet growth factors}

As already stated, intact platelets contain alpha-granules and other granular bodies in which important mediator molecules are stored, and are released from the platelet following activation. Among these are the growth factors (GFs), which when released from activated platelets, exhibit an extensive tissue forming ability, such as the initiation and modulation of wound healing in both soft and hard tissues (Anitua et al., 2004; Harrison \& Cramer, 1993; Lacoste et al., 2003; Weibrich et al., 2002). (See Table 1. and Table 4.)

\begin{tabular}{|c|c|}
\hline $\begin{array}{l}\text { IL-1ß, Interleukin } \\
\text { 1beta }\end{array}$ & $\begin{array}{l}\text { - stimulates lymphocyte proliferation } \\
\text { - influences collagenase activity }\end{array}$ \\
\hline IL-8, Interleukin 8 & $\begin{array}{l}\text { - chemotactic for all known types of migratory immune cells } \\
\text { - } \text { specifically activates neutrophile granulocytes } \\
\text { - mitogen for epidermal cells }\end{array}$ \\
\hline $\begin{array}{l}\text { EGF-1, Epidermal } \\
\text { growth factor (beta- } \\
\text { Urogastron) }\end{array}$ & - stimulates re-epithelization, angiogenesis, and collagenase activity \\
\hline $\begin{array}{l}\text { bFGF/ FGF-2, } \\
\text { Fibroblast growth } \\
\text { factor (basic) }\end{array}$ & $\begin{array}{l}\text { - stimulates angiogenesis, endothelial cell proliferation, collagen } \\
\text { synthesis, wound contraction, matrix synthesis, epithelization, } \\
\text { keratinocyte growth factor production }\end{array}$ \\
\hline $\begin{array}{l}\text { aFGF/ FGF-1, } \\
\text { Fibroblast growth } \\
\text { factor (acidic) }\end{array}$ & $\begin{array}{l}\text { most potent GF identified thus far for skin keratinocytes playing } \\
\text { role in tissue repair following skin injuries. }\end{array}$ \\
\hline $\begin{array}{l}\text { KGF/ FGF-7 } \\
\text { Keratinocyte growth } \\
\text { factor }\end{array}$ & $\begin{array}{l}\text { - growth and development of progenitors of granulocytes and } \\
\text { macrophages, stimulates myeloblasts and monoblasts and triggers } \\
\text { their irreversible differentiation, synergises with EPO in the } \\
\text { proliferation of erythroid and megakaryocytic progenitor cells, in } \\
\text { combination with another colony stimulating factor, M-CSF, } \\
\text { synergically suppresses the generation of macrophage-containing } \\
\text { cell colonies } \\
\text { - for some types of blast cells acute myeloid leukemia acts as an } \\
\text { autocrine mediator of growth. } \\
\text { - a strong chemoattractant for neutrophils, enhances microbicidal } \\
\text { activity, oxidative metabolism, and phagocytic activity of } \\
\text { neutrophils and macrophages, improves their cytotoxicity }\end{array}$ \\
\hline $\begin{array}{c}\text { GM-SCF/CSFa, } \\
\text { granulocyte/macropha } \\
\text { ge colony-stimulating } \\
\text { factor alpha }\end{array}$ & $\begin{array}{l}\text { - stimulates both the proliferation and the differentiated function in } \\
\text { osteoblasts. }\end{array}$ \\
\hline $\begin{array}{l}\text { IGF-1 } \\
\text { Insulin-like growth } \\
\text { factor }\end{array}$ & $\begin{array}{l}\text { a growth factor for normal fibroblasts, promotes the synthesis of } \\
\text { collagenase and prostaglandin E2 in fibroblasts, may function also } \\
\text { as an autocrine growth modulator for human chronic lymphocytic } \\
\text { leukemia cells in vivo, an autocrine growth modulator for } \\
\text { neuroblastoma cells, the autocrine growth-promoting activity is } \\
\text { inhibited by IL4. }\end{array}$ \\
\hline $\begin{array}{l}\text { TNF- a } \\
\text { Tumor necrosis } \\
\text { factor alpha }\end{array}$ & $\begin{array}{l}\text { - Besides its immune functions, TNF is a potent promoter of } \\
\text { angiogenesis in vivo. TNF-alpha is a growth factor for human } \\
\text { fibroblasts, where it promotes the synthesis of collagenase and } \\
\text { prostaglandin E2 }\end{array}$ \\
\hline
\end{tabular}




\begin{tabular}{|c|c|}
\hline & $\begin{array}{l}\text { - promotes the proliferation of astroglial cells and microglial cells } \\
\text { and therefore may be involved in pathological processes such as } \\
\text { astrogliosis and demyelinisation. }\end{array}$ \\
\hline $\begin{array}{l}\text { PDGF A } \\
\text { Platelet derived } \\
\text { growth factor A }\end{array}$ & $\begin{array}{l}\text { - PDGF isoforms are potent mitogens for connective tissue cells, } \\
\text { including dermal fibroblasts, arterial smooth muscle cells, } \\
\text { chondrocytes and some epithelial and endothelial cells } \\
\text { - chemotactic and mitogenic for fibroblasts and smooth muscle cells, } \\
\text { neutrophils and mononuclear cells } \\
\text { - activates TGF- } \beta \text {, stimulates neutrophils and macrophages, } \\
\text { stimulates chemotaxis, mitogenesis of fibroblasts and smooth } \\
\text { muscle cells, collagen synthesis and collagenase activity, } \\
\text { angiogenesis } \\
\text { - a major mitogen for connective tissue cells and certain other cell } \\
\text { types } \\
\text { - stimulates cell growth, but also changes cell shape and motility; } \\
\text { induces the reorganization of the actin filament system and } \\
\text { stimulates chemotaxis, i.e., a directed cell movement toward a } \\
\text { gradient of PDGF }\end{array}$ \\
\hline $\begin{array}{l}\text { PDGF B } \\
\text { Platelet derived } \\
\text { growth factor B }\end{array}$ & $\begin{array}{l}\text { - regulates the proliferation and the differentiation of multiple cell } \\
\text { types. TGF found in platelets is subdivided into TGF a and } \beta \text {, } \\
\text { which are the more generic connective tissue growth factors } \\
\text { involved with matrix formation influencing osteoblasts to lay } \\
\text { down bone matrix through the process of osteogenesis. } \\
\text { - TGF } \beta 1 \text { and TGF } \beta 2 \text { activate fibroblasts, endothelial and osteoprogenitor } \\
\text { cells, chondroprogenitor cells and mesenchimal stem cells. A } \\
\text { chondroprogenitor cell will further differentiate and produce the } \\
\text { matrix for cartilage. A mesenchymal stem cell stimulated to mitose } \\
\text { provides wound healing cells }\end{array}$ \\
\hline $\begin{array}{c}\text { TGF-a, } \\
\text { Transforming } \\
\text { growth factor alpha }\end{array}$ & $\begin{array}{l}\text { - stimulates mesenchymal, epithelial, and endothelial cell growth, } \\
\text { endothelial chemotaxis }\end{array}$ \\
\hline $\begin{array}{l}\text { TGF- } \$ 1 \text {, } \\
\text { Transforming } \\
\text { growth factor } \$ 1\end{array}$ & $\begin{array}{l}\text { - stimulates monocytes to secrete FGF, PDGF, TNF- } \alpha \text {, Interleukin-1 } \\
\text { - stimulates fibroblast chemotaxis and proliferation } \\
\text { - stimulates collagen synthesis } \\
\text { - decrease dermal scarring }\end{array}$ \\
\hline $\begin{array}{l}\text { VEGF/ VEP } \\
\text { Vascular endothelial } \\
\text { growth factor }\end{array}$ & $\begin{array}{l}\text { - highly specific mitogen for vascular endothelial cells } \\
\text { - influences vascular permeability and is a strong angiogenic protein and } \\
\text { probably also plays a role in neovascularisation under physiological } \\
\text { conditions } \\
\text { - in endothelial cells, VEGF induces the synthesis of von Willebrand } \\
\text { factor. } \\
\text { - a potent chemoattractant for monocytes and thus has procoagulatory } \\
\text { activities. } \\
\text { - in microvascular endothelial cells induces the synthesis of plasminogen } \\
\text { activator and plasminogen activator inhibitor type } 1 \text {. } \\
\text { - induces the synthesis of the metalloproteinase, interstitial collagenase, } \\
\text { which degrades interstitial collagen type } 1 \text {, collagen type 2, and } \\
\text { collagen type } 3 \text { under normal physiological conditions. }\end{array}$ \\
\hline
\end{tabular}

Table 4. Platelet growth factors (Modified from http://www.copewithcytokines.de/cope.coi) 
Growth factors modulate the functional activities of individual cells and tissues, mediate interactions between cells directly and regulate processes taking place in the extracellular environment in autocrine, paracrine, iuxtacrine or retrocrine fashion. GFs work by binding to specific cell surface receptors and can target cells in a number of recognized ways or modes. Release of these substances into the blood stream allows them to get to distant targets (endocrine mode), diffuse over short distances to affect other cells (juxtacrine mode), and to influence neighbouring cells (paracrine mode). Growth factors can even act on the cell in which they are produced (autocrine mode). These different modes are all likely to be operative during tissue repair.

The most important GFs released by the platelets are PDGF (the platelet derived growth factor), TGF- $\alpha$ \& $\beta$ (transforming growth factor alpha \& $\beta$ ), EGF (epidermal growth factor), FGF (fibroblast growth factor), IGF (insulin growth factor), PDEGF (platelet derived epidermal growth factor), PDAF (platelet derived angiogenesis factor), IL-8 (interleukin-8), TNF-a (tumour necrosis factor alpha), CTGR (connective tissue growth factor), GM-CSF (granulocyte macrophage colony stimulating factor), KGF (keratinocyte growth factor), and Ang-2 (angiopoetin) (Frechette et al., 2005; Borzini \& Mazzucco, 2005; Westerhuis et al., 2005; Everts et al., 2006) (see Table 4.). Beside these GFs, there are at least 60 different biologically active substances in the platelets that are involved in tissue repair mechanisms such as chemotaxis, cell proliferation and differentiation, angiogenesis, extracellular matrix deposition, immune modulation, antimicrobial activity, and remodelling (Borzini \& Mazzucco, 2007). All these functions have been demonstrated in numerous in vitro (Phillips et al., 1994; Dankert, 1995; Brill et al., 2004; Cenni et al., 2005; Kark et al., 2006) and in vivo experiments (Debus et al., 2001; Kevy et al., 2004).

\section{Therapeutic platelet products}

Even the topically applied fibrin glue itself improves the haemostasis, reduces blood loss, and tightens the sealing of sutures due to fibrin formation, providing a stabilized matrix for ingrowing fibroblasts and therefore promoting the support of the granulation tissue, revascularization and re-epithelization. Further inclusion of growth factor containing platelets into this concept of tissue regeneration provided and increased tissue repair and regeneration. Various types of platelet products, such as platelet rich plasma, plateletleukocyte gel and platelet gel, derived from autologous or allogeneic peripheral blood, have been tested for tissue repair.

\subsection{Platelet-rich plasma}

Platelet-rich plasma (PRP) is defined as a portion of the plasma fraction of autologous blood having a platelet concentration above baseline. Usual product of blood banking is the allogeneic platelet concentrate or platelet-rich plasma, obtained from random blood donors. Autologous platelet rich plasma preparations involve the procurement of $50-100 \mathrm{ml}$ of blood drawn from the patient at the point of care. The blood is processed using PRP devices yielding $5-10 \mathrm{ml}$ of concentrated PRP (3 to $5 \mathrm{X}$ baseline levels). PRP serves as a growth factor vehicle and has both mitogenic and chemotactic properties. It contains a high level of platelets and a full complement of clotting and growth factors (Lacci \& Dardik, 2010). The PRP is then activated and applied to the wound site or mixed with bone material for 
implantation. This procedure is usually performed in under an hour by a well trained and qualified technician.

\subsection{Platelet gel}

Autologous platelet-gel (PG) is the result of harvesting one's own cells (platelets) that are concentrated by means of centrifugation and exposed to an agonist, which induces activation resulting in the release of intrinsic substances that are applied to the target area where they accelerate wound healing. Autologous PG is attractive because it concentrates a large number of biologically active substances, which are primarily proteins that participate in a complex series of mechanisms involved in inflammation and wound healing (Everts et al., 2006; Stammers et al., 2009; Tschon et al., 2011; Mehta \& Watson, 2008). Lately, the possible use of allogeneic PG with similar results was demonstrated in our study (Smrke et al. 2007).

\subsection{Platelet-leukocyte gel}

Platelet-leukocyte gel contains high concentrations of platelets and leukocytes. As leukocytes play an important role in the innate host-defence, PLG might have antimicrobial properties. A unit of whole blood is centrifuged to obtain platelet-leukocyte-rich plasma (PLRP). The PLG is then formed by mixing P-LRP with a thrombin-calcium chloride preparation. Similar to PG, the treatment with PLG provides a source of concentrated platelets, with granules that contain growth factors. In addition the high content of nonactivated leukocytes, present in the PLG, promotes anti-microbial activity at the wound site through the destruction of bacteria and foreign materials and the removal of damaged tissue (Everts et al, 2006b; Everts et al. 2008).

Platelet gel can be nowadays prepared using a range of commercially available instruments from a number of manufactures. There are no uniform manufacturing standards for platelet gel in existence, which has disturbed the classical blood banking. The existing literature adds controversies to the use of PLT concentrates. When talking about platelets and their products, a great number of variables have to be considered. These variables are mainly related to the PRP preparation methods, the type of activators used, intra- and inter-species variability, types of pathology to be treated, the ways and times of administration and the association of PRP or PG with other treatments. The improved knowledge on the variables affecting therapeutic efficacy will surely help in addressing the best combination of factors implied in the different steps of PLT concentrate preparation and use (Mazzucco et al., 2009).

\section{Activation of PRP and the formation of the gel}

The typical source of platelet GFs is platelet-rich plasma (PRP) - Figure 4A. Platelet gel (PG) is formed after the PRP is exposed to a strong coagulation stimuli, which is usually the addition of thrombin and calcium (to counteract the anticoagulant citrate if plasma is citrated) ( Mazzucco et al., 2004; De Somer et al., 2006) or some other fibrinogen-digestion based activator, such as batroxobine from the viper Bothrops atrox snake venom ( Carr et al., 2003; Mazzucco et al., 2008).

Consequently, platelet activation and a coagulation cascade follow in a positive loop fashion, which finally results in the formation of a thrombus-like gelatinous substance - 
platelet gel. (See Figures 4B, 4C). In the gel, activated platelets are trapped in a fibrin network and they release their active substances, which slowly diffuse into the surroundings. The final result - platelet gel - can be shaped according to the needs, put on different vehicles such as medical gauze or even advanced types of biocompatible carriers and scaffolds, such as fibrin or hyaluronic acid, and used topically. It can be used as a vehicle for the stem cells and ground cancellous bone transplant, allowing the formation and shaping of grafts with determined shapes (See Fig. 4D).

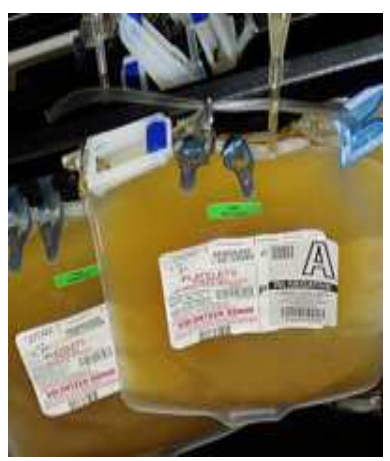

A.

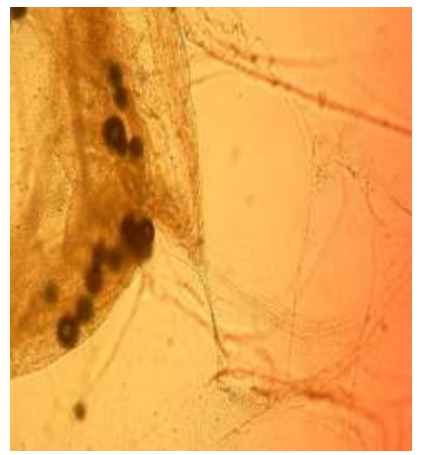

C.

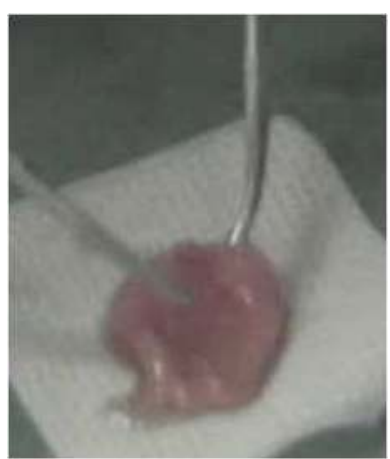

B.

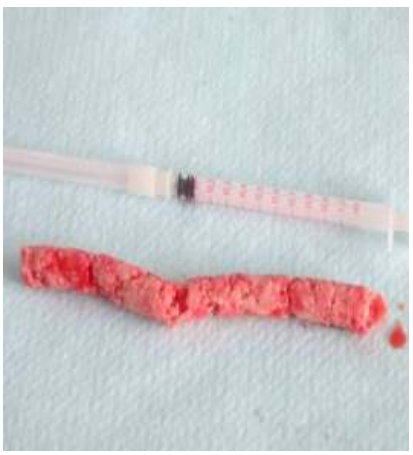

D.

Legend: A. Platelet rich plasma; B.Platelet gel; C: Microscopical view of the platelet gel. Inverted microscope Nikon Eclipsete 300, $10 x$ enlarged.; D: Graft with the shape used for mandibular deffects, containing PG, stem cells and cancellous bone

Fig. 4. Platelet gel

At the beginning autologous $\mathrm{PRP} /$ platelet gel was developed as a by-product of multicomponent apheresis (Rosenthal et al, 1975). Later several systems became available to prepare PRP and from this, the platelet gel. These systems produce two- to six-fold platelet enriched concentrations. Very few data have been reported on the kinetics of growth factor release from PRP-gels. The bioavailability of growth factors in tissue healing depends on the amount of growth factors stored in the platelets but a portion of these is lost during platelet manipulation. In one report, three commercially available devices (Fibrinet, RegenPRP-Kit, Plateltex) and one manual procedure (home-made) were evaluated with reference to the 
resulting platelet concentration, growth factor content and the kinetics of growth factor release from the gel. Similar methods for platelet gel preparation have revealed different performances concerning the growth factor recovery and the kinetics of its release from the gel. It is unclear whether these noticeable differences are important for clinical management (Mazzucco et al., 2009).

Some research groups have successfully engineered kits for platelet gel formation, such as REGENLAB® and PLATELTEX®, which include sodium carboxymethylated cellulose fibres (Hydrofibre $^{\mathrm{TM}}$ ) as a biocomposite-scaffold, entrapping human platelets in PRP. The PLATELTEX® activation kit, popular in Europe, ensures very rapid gelation and the production of platelet and fibrin gel for acute and chronic ulcer treatment. This reduces spillage of the gel during topical application. The new generation of PRP activation, provides for excellent platelet recovery, collection efficiency and PDGF-AB availability. Gelation of the PRP is induced by the enzyme batroxobin, which does not exert pharmacological activity after topical gel administration. In Europe, clinical trials have been authorised using PRP-gel preparation including activation with batroxobin. PRP-gel has not been considered a somatic cell therapy product.

Platelets treated with thrombin become activated and they release their growth factors quickly. Furthermore, thrombin-platelet interaction is a physiological mechanism that hastens the clot-retraction rate. On the contrary, platelets treated with batroxobin do not become activated; they are passively entrapped within the fibrin network, and their growth factor release occurs slowly. In these conditions, the clot retraction takes longer to occur. According to these differences between thrombin and batroxobin, it is expected that batroxobin-induced PRP activation will tailor the slow release of the platelet content, thus providing longer in loco availability of trophic factors. In selected clinical conditions, this durable anabolic factor availability might be preferable to a quick thrombin-induced growth factor release (Mazzucco et al, 2008).

An alternative means of PRP activation was documented in 2007, when PRP was pulsed with one $300 \mathrm{~ns}$ pulse with an electric field of $30 \mathrm{kV} / \mathrm{cm}$, platelets aggregated and a platelet gel was produced (Zhang et al., 2008).

The lack of effective delivery and the efficient targeting specificity limits clinical applications of platelet gel. In 2008, heparin possessing PDGF binding domain was crosslinked to the collagen-based demineralized bone matrix (DBM) for the delivery of human PDGF. In in vitro experiments, heparin improves the binding of PDGF to collagen. The in vitro activity assay indicates that the collagen-heparin-PDGF (CH-PDGF) complex promotes human fibroblasts to proliferate on collagen gel. In addition, $\mathrm{CH}-\mathrm{PDGF}$ stimulates cells to migrate into DBM scaffolds after implantation. The histological analysis shows that CH-PDGF promotes the vascularization of the implants. In summary, heparin-DBM/PDGF could prevent the diffusion of PDGF, prolong its activity, and promote the cellularization and vascularization of the scaffold (Sun et al., 2009).

Recent findings on multiple biological properties of human umbilical cord blood (UCB) and its high level of viral safety prompted some authors to investigate the characteristics of its platelets and the possibility of producing PG from cord blood. UCB-derived PG releases high levels of vascular endothelial growth factor (VEGF) and platelet-derived growth factor-BB (PDGF-BB), substantial amounts of fibroblast growth factor (FGF), hepatocyte growth factor (HGF) and transforming growth factor-beta 1 (TGFbeta1), and minimal amounts of PDGF-AB. These findings suggest that UCB-derived PG can be a preferable tool for tissue engineering applications where high levels of VEGF and PDGF may be desirable (Parazzi et al., 2010). 


\section{The results of recent clinical research}

The results of clinical research indicate that platelet-derived growth factors act in synergy with plasma-derived factors to activate a complex network of autocrine functions that modulate and enhance healing. Therefore, autologous platelet rich plasma (PRP) in the form of activated platelet gel and recombinant morphogenic proteins have been used for healing all kinds of tissues with various results.

\subsection{Chronic wounds}

When the fibroblasts were sealed in the wound with fibrin to which platelet releasate was added, a cellular infiltrate that had characteristics of granulation tissue invaded the wound space. Platelet releasate appeared to be an additional requirement for the early induction of granulation tissue and for enhanced granulation tissue accumulation. It is now widely accepted that the correct strategy to promote the wound-healing cascade is to prepare an autologous PRP/platelet gel that contains growth factors, and administer it directly to sites of surgical interventions or injuries.

Patients suffering from diabetes mellitus, are seventeen times more likely to develop gangrene and five out of six major limb amputations occur in diabetic patients. In the United States, the diabetic foot problem accounts for $20 \%$ of all diabetic hospital admissions and $50 \%$ of all non-traumatic amputations. Ulcers occur in $15 \%$ of diabetics, and $6-20 \%$ of all hospitalized diabetic patients have foot ulcers. The topical use of platelet rich plasma may play an important role in the initiation of the repair process of chronic wounds. Many patients can be treated at home without difficulty, requiring only periodic outpatient examination (Steed et al., 1992; Millington and Norris, 2000; Borzini, 2006). Although some of the earlier studies resulted in poor outcomes (Reutter et al.,1999), newer studies tend to produce much better results.

\subsection{Bone}

Platelet gel is very effective in formation of new bone when applied together with cancellous bone containing stem cells for treatment of non healing of long bone fractures (Smrke et al., 2007). Platelet gel enhanced the bone formation contrary to the using of plasma alone as measured by quantity of incorporated bone both in vitro and in vivo (Geuze et al., 2009). In an article presented in 2010, 115 patients with finger amputations or wounds were treated with platelet gel. Loss of bone tissue represented an obstacle to the total tissue recovery, but the aesthetic results were satisfactory in nearly all cases, the recovery of soft tissue in all patients ranged from 80 to $100 \%$ (Balbo et al., 2010). However, platelet gel was ineffective for the spinal fusions where it failed to enhance fusion rate when added to autograft in patients undergoing instrumented posterolateral spinal fusion so several authors do not recommend its use to supplement autologous bone grafting during instrumented posterolateral spinal fusion ( Castro, 2004; Burkus, 2005; De Somer et al., 2006; Savarino et al., 2006).

\subsection{Tendons and ligaments}

Tendons and ligaments naturally have poor blood supply. Damage most often occurs in the knee, ankle, shoulder, elbow, wrist, biceps, calf, hamstrings and Achilles tendons. The use of platelet gel has been generally well tolerated by the patients and it resulted in significant increase of healing parameters. Platelet injection therapy has changed the way orthopedic specialists treat sports injury patients. Usually PRP is injected into the damaged area using 
minimally invasive protocols that involve ultrasonically guided platelet rich plasma (PRP) injections. (Everts et al. 2007; Everts et al.,2008; Gardner et al., 2006).

\subsection{Aesthetic surgery}

There is especially extensive marketing for the use of PRP in aesthetic surgery and lifting (Bhanot \& Alex, 2002; Powell et al., 2001). Private organisations tend to offer this therapy throughout the world. They offer PRP delivery by various instruments into the skin tissues, rendering good aesthetic effects (see Figure 5). The indications include facelifts, browlifts, the creation of flaps, blepharoplasty, mammaplasties, and abdominoplasties. PRP enhanced grafts generally had a higher graft acceptance and better graft retention than traditional fat grafting techniques, along with decreased swelling and bruising in the donor sites (Sclafani et al., 2005; Brown et al, 2006).

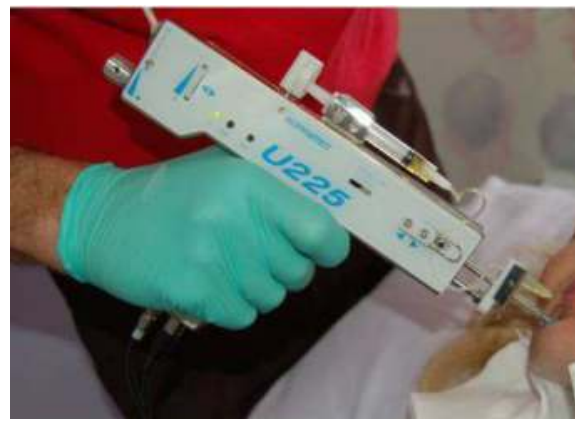

A

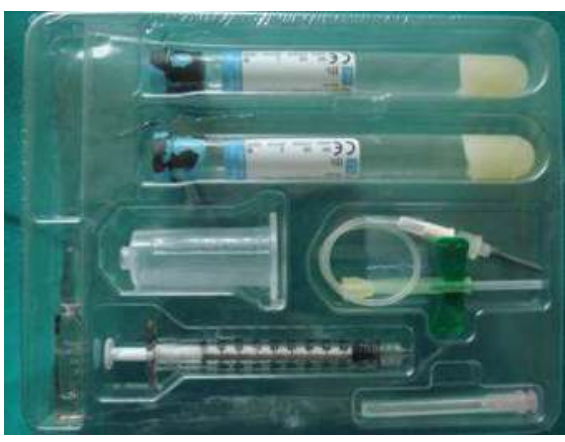

C

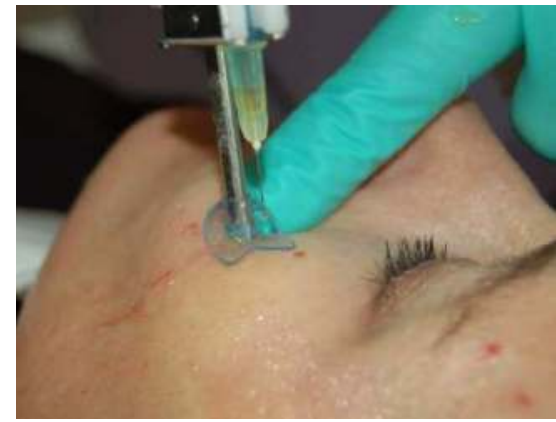

B

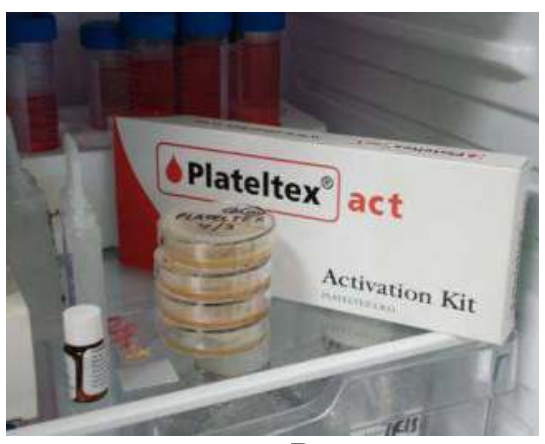

$\mathrm{D}$

Legend: A: The instrument Mesogun for delivering PRP (U225)as marketed by company Boland; B: The needle depth can be accurately set for precise delivery; $C$ : An example of kit for PRP preparation and application from Omnimed (Pty)., Ltd., JHB, South Africa; D: An example of platelet gel activation kit PLATELTEX® (http://www.bolandcell.co.za/platelet.htm)

Fig. 5. Use of autologous platelet-rich plasma (PRP).

\subsection{Cardiovascular}

Wound infection is a devastating complication after cardiovascular surgery. This can lead to surgical reoperation, prolonged intensive care unit stay, and increased mortality promoting 
the raising the cost of cardiac surgery while decreasing the patient quality of life. The antimicrobial action of white blood cells and platelets, both found in the platelet gel, may reduce the potential for infection to develop during cardiac surgery. Various protocols have documented such an improved healing of surgical wound in cardiac surgery (Mogan and Larson, 2004; Trowbridge et al,2005; Englert et al., 2008; Gunyaqdin et al., 2008)

\subsection{Oral and craniofacial surgery}

As mentioned, the oral surgeons were the leading community in the use of platelet gel for transplantation of artificial and natural grafts. Platelet gel reached a huge popularity in maxillofacial settings where it is considered standard treatment of bone defects, artificial endosseal implants, oral reconstructions, maxillary sinus augmentation, etc. (Marx et al., 1998; Belli et al., 2005; Pomerantz and Dutton, 2005; Mendez et al., 2006).

\subsection{Other applications}

Platelet gel has been successfully used for ocular diseases, such as for enhanced healing of corneal surface and ocular surgery (Koffler, 2006; Liu et al.,2006; Lee \& Kang, 2011).

Lately, the studies of PG use addressed some unexpected fields of medicine. For instance, PG was used as a safe and effective tool in the management of mucosal skin lesions related to the graft- versus-host disease GVHD. Six patients with multiple lesions involving dermis, subcutaneous or oral mucosa and related to GVHD underwent PLT gel as local therapy. After the second PLT gel application, the pain disappeared in all cases and the granulation tissue was observed in the four patients, five of six patients showed a complete response, while one patient with a partial response died early from multiorgan failure (Picardi et al., 2010).

Platelet gel mixed with centrifuged fat tissue has been successfully applied for the patients affected by Parry - Romberg Syndrome (progressive hemifacial atrophy and volumetric deficit), which is an uncommon degenerative and poorly understood condition. It is characterized by a slow and progressive atrophy affecting one side of the face. The atrophy progresses slowly for several years and becomes stable. After stabilization of the disease, plastic surgery of autologous fat grafts can be performed. Study suggested a therapeutic plan comprised of two sequential treatments: acquisition of platelet gel from a small volume of blood $(9 \mathrm{ml})$ followed by the Coleman technique for reconstructing the three-dimensional projection of the face contour, restoring the superficial density of the facial tissues. The results obtained prove the efficacy of these two treatments combined, and the satisfaction of the patient confirms the quality of the results. (Cervelli \& Gentile, 2009).

Recently it is surprisingly becoming clear that platelets have a definite role in the cancer, which is probably due to their pro-angiogenesis stimulation and regulation of new blood vessel growth through numerous stimulators and inhibitors of angiogenesis, such as endostatin and VEGF, by several pathways. Cancer cells probably preferentially stimulate platelets to secrete their pro-angiogenic payload, which is counteracted by the anti-platelet agent aspirin that inhibits the platelet-mediated angiogenesis (Elisabeth et al., 2011).

\section{Pros and cons of platelet gel therapies}

The common advantages of the PG driven healing can be summarized as follows: there seems to be a complete absence of keloid formation, as far as pathologic hyperplasia, metaplasia or dyschromia of the healed lesion (Pomerantz et al., 2005, Lundblad \& White, 2005). Other advantages are comfort and pain diminution (Pomerantz et al., 2005, Mendez et 
al., 2006), less oedema and ecchymosis (Powell et al., 2001; Mendez et al., 2006; Brown et al., 2006). Particularly valuable advantages are reported through literature: reduced mortality after cardiac surgery (Trowbridge et al., 2005), reduced infection rate after cardiac and orthopaedic surgery (Gilsanz et al., 2001; Salvadè et al., 2010), reduced transfusion supply and hospital stay after orthopaedic surgery (Gardner et al., 2006), reduced amputation rate in diabetic foot (Knighton et al., 1990). PRP therapy became very popular in the USA, which was due to the fact that it attracted enormous attention after the Super Bowl finals in 2009, when the athletes promoted it on TV (Donald, 2011).

Drawbacks of PG therapies are far less pronounced. It is interesting that besides the considerable variability of the clinical studies, PG therapy had practically no or only minute ill effects when compared to standard therapies. Owing to the high heterogeneity of the products, a need for standardization is a commonly shared sentiment. Heterogeneous production generates heterogeneous products which, in turn, have distinct biological properties and healing capacities (Zimmermann et al., 2003; Eppley et al., 2006; Fried et al., 2006).

Considering that heterogeneity involves products, clinical conditions, tissues to be cared for, treatment protocols and probably many other minor variables, authors strongly support the project for the establishment of a clinical database in order to collect enough data for multivariate analysis of the clinical results (Kantor \& Margolis, 2000).

\section{The dilemma of allogeneic vs. autologous platelet gel}

In the majority of clinical applications autologous platelets were used for the platelet gel formation. As mentioned previously, autologous PG products are prone to enormous variability, resulting in scientific scepticism and disbelief regarding the actual value of this method. In our study in 2007, we used instead allogeneic PRP. We reported a case of a 50year-old type II diabetic male with a comminuted fracture of the tibia and delayed union after insufficient initial osteosynthesis with a resulting pseudarthrosis, who was treated operatively by using a graft composed of allogeneic platelet gel mixed with autologous cancellous bone. Due to a history of diabetes, allogeneic instead of autologous platelets that were $\mathrm{ABO}$ and $\mathrm{RhD}$ matched, leukocyte depleted, irradiated and activated by human thrombin were used. No side effects were observed and no immune reactions such as platelet- or HLA-class I antibodies were detected (Smrke et al., 2007).

We explored several advantages of allogeneic platelets, as compared to the classical autologous setting. Allogeneic platelet units from the blood bank are available in larger quantities, they are safe and affordable, they are highly standardized in terms of platelet, residual leukocyte and red blood cell content, the centrifugal forces used for their isolation, the temperature of the centrifugation, techniques of separation and processing and the composition of the preservative solution, as mandated by international standards in USA and Europe. In addition, they are constantly resuspended on agitators in a standard manner (Brecher, 2005; Council of Europe, 2011). On the other hand, autologous platelet preparations are subject to enormous variability, which hinders serious clinical studies.

The extensive use of allogeneic platelets could, beside the regenerative medicine, influence the blood transfusion policies in future. The platelet units have a short shelf life of $3-7$ days and are therefore prone to outdating, regardless of the best practices performed. In 2001 in USA, at least 1,234.000 out of a total of 12,898.000 produced platelet units $(9.5 \%)$ were outdated and discarded (Sullivan et al, 2007). In another study, expiry rates of platelet units were different in various hospitals, ranging between $2 \%$ and $13.8 \%$ (Novis et al, 2002). It is 
clear from these figures that a considerable amount of platelet units are routinely discarded, which could be reversed by the utilization of frozen units in regenerative purposes, such as platelet gel preparation.

Besides, the use of platelet gel could have an important impact on economy of medicine. Let us focus only at the therapy of chronic wound with the platelet gel. Ulcer secondary to venous hypertension and venous insufficiency is the most common chronic wound with 57$80 \%$ incidence of all chronic wounds. Average incidence is 15-30 in 100.000 persons and they account for nearly $70 \%$ of all leg ulcers (Margolis et al., 2001). All these conditions are more prevalent in elderly population, which represents $20 \%$ of the total, a figure that is likely to increase to $25 \%$ by 2020 . In addition, the increased occurrence and longevity of these ulcers are further compounded by the detrimental effects ageing has on the skin and the wound healing process. Chronic wounds significantly impair the quality of life of more than 9 million of people worldwide and account for a disproportionate share of healthcare expenditures: it is estimated that yearly treatment cost for health care systems averages 9 $12 \mathrm{k} €$ per each patient. Even with increasing knowledge and the development of more sophisticated interventions, many clinicians encounter wounds that are hard-to-heal where, despite best efforts, wound healing is prolonged or never achieved (Moffatt, 2008). Indeed, chronic and hard-to-heal wounds are a challenge to the health care professionals. Thus, in the frame of progressively ageing population, the efficient therapy for chronic wounds and tissue reparation promises improving life quality and combating rising healthcare costs. Currently available and practiced therapies such as wound dressings, pentoxifylline, laser and intermittent pneumatic compression treatments applied in concomitance with compressive bandages have shown rather disappointing overall outcomes except some encouraging results obtained by combination of compression and bilayer of artificial skin (Palfreyman et al., 2006).

\section{Conclusion}

Platelets are intriguing cellular particles that have, in the course of human and animal evolution, beside their specialisation into the haemostasis, kept some other abilities of their predecessors - universal blood cells - the abilities of immune defence and tissue forming. For the purpose of tissue forming, platelets can also be used therapeutically. Autologous or allogeneic blood can be used for this purpose and centrifuged to produce a platelet concentrate, which is then further in vitro activated to form a thrombus-like gelatinous substance - the platelet gel. Many in-vitro studies have established that platelet- derived growth factors accelerate proliferation of an array of cells involved in soft and bony tissue regeneration. These effects have also been evaluated and confirmed by numerous in vivo, both in animal and human clinical studies. Consequently, we can say that the platelet-derived products currently represent a valuable therapeutic modality, offering opportunities for various applications in regenerative medicine and tissue engineering.

\section{Acknowledgment}

The authors acknowledge the kind assistance of Petra Pavlovčič in prepairing the manuscript. 


\section{References}

Altman, D.G., Schulz, K.F., Moher, D., Egger, M., Davidoff, F., Elbourne, D., Gotzsche, P.C. \& Lang, T. (2001). The revised CONSORT statement for reporting randomized trials: explanation and elaboration. Ann Intern Med, Vol.134, No.8, (April 2001), pp. 663-94, ISSN 0003-4819

Anderson, K. \& Baker, S. (2003). Advances in facial rejuvenation surgery. Curr Opin Otolaryngol Head Neck Surg, Vol.11, No.4, (August 2003), pp. 256-60, ISSN 1068-9508

Anitua, E., Andia, I., Ardanza, B., Nurden, P. \& Nurden, A.T. (2004). Autologous platelets as a source of proteins for healing and tissue regeneration. Thromb Haemost, Vol.91, No.1, (January 2004), pp. 4-15, ISSN 0340-6245

Balbo, R., Avonto, I., Marenchino, D., Maddalena, L., Menardi, G. \& Peano, G. (2010). Platelet gel for the treatment of traumatic loss of finger substance. Blood Transfus, Vol.8, No.4, (October 2010), pp. 255-9, ISSN 1723-2007

Battinelli, E.M., Markens, B.A. \& Italiano, J.E., Jr. (2011). Release of angiogenesis regulatory proteins from platelet alpha granules: modulation of physiological and pathological angiogenesis. Blood, Epub ahead of print June 16 (June 2011), doi: 10.1182/blood-2011-02-334524, ISSN 1528-0020

Belli, E., Longo, B. \& Balestra, F.M. (2005). Autogenous platelet-rich plasma in combination with bovine-derived hydroxyapatite xenograft for treatment of a cystic lesion of the jaw. J Craniofac Surg, Vol.16, No.6, (November 2005), pp. 978-80, ISSN 1049-2275

Bernuzzi, G., Tardito, S., Bussolati, O., Adorni, D., Cantarelli, S., Fagnoni, F., Rossetti, A., Azzarone, M., Ficarelli, E.,Caleffi, E., Gazzola, G. \& Franchini, M. (2010). Platelet gel in the treatment of cutaneous ulcers: the experience of the Immunohaematology and Transfusion Centre of Parma. Blood Transfus, Vol.8, No.4, (October 2010), pp. 237-47, ISSN 1049-2275

Bhanot, S. \& Alex, J.C. (2002). Current applications of platelet gels in facial plastic surgery. Facial Plast Surg vol.18, No.1, (February 2002), pp.27-33, ISSN 0736-6825

Borzini, P. \& Mazzucco, L. (2005). Tissue regeneration and in loco administration of platelet derivatives: clinical outcome, heterogeneous products, and heterogeneity of the effector mechanisms. Transfusion, Vol.45, No.11, (November 2005), pp. 1759-67, ISSN 0041-1132

Borzini, P., Mazzucco, L., Giampaolo, A. \& Hassan, H.J. (2006). Platelet gel - the Italian way: a call for procedure standardization and quality control. Transfus Med, Vol.16, No.4, (August 2006), pp. 303-4, ISSN 0958-7578

Borzini, P. \& Mazzucco, L. (2007). Platelet-rich plasma (PRP) and platelet derivatives for topical therapy. What is true from the biological view point? ISBT Science Series, Vol.2, No.1, (July 2007), pp. 272-81, ISSN 1751-2816

Brandstedt, S., Rank, F.\& Olson, P.S. (1980). Wound-healing and formation of granulationtissue in normal and defibrinogenated rabbits - an experimental-model and histological study. Eur Surg Res, Vol.12, No.1, (1980), pp. 12-21, ISSN 0014-312X

Brecher, M.E., (Ed.). (2005). Technical Manual, 15th Edition, American Association of Blood Banks, ISBN 1-56395-196-7, Bethesda 
Brill, A., Elinav, H. \& Varon, D. (2004). Differential role of platelet granular mediators in angiogenesis. Cardiovasc Res, Vol.63, No.2, (August 2004), pp. 226-35, ISSN 00086363

Brown, S.A., Appelt, E.A., Lipschitz, A., Sorokin, E.S. \& Rohrich, R.J. (2006). Platelet gel sealant use in rhytidectomy. Plast Reconstr Surg, Vol.118, No.4, (September 2006), pp. 1019-25, ISSN 0032-1052

Burkus, J.K. (2005). Surgical treatment of the painful motion segment: matching technology with indications. Spine, Vol.30, No.16 Suppl, (August 2005), pp. 7-15, ISSN 03622436

Carreon, L.Y., Glassman, S.D., Anekstein, Y. \& Puno, R.M. (2005). Platelet gel (AGF) fails to increase fusion rates in instrumented posterolateral fusions. Spine, Vol.30, No.9, (May 2005), pp. E243-46, ISSN 0362-2436

Castro, F.P., Jr. (2004). Role of activated growth factors in lumbar spinal fusions. J Spinal Disord Tech, Vol.17, No.5, (October 2004), pp. 380-4, ISSN 1536-0652

Carr, M.E., Jr., Carr, S.L., Tildon, T., Fisher, L.M. \& Martin, E.J. (2003). Batroxobin-induced clots exhibit delayed and reduced platelet contractile force in some patients with clotting factor deficiencies. J Thromb Haemost, Vol.1, No.2, (February 2003), pp. 2439, ISSN 1538-7933

Cenni, E., Ciapetti, G., Pagani, S., Perut, F., Giunti, A. \& Baldini, N. (2005). Effects of activated platelet concentrates on human primary cultures of fibroblasts and osteoblasts. J Periodontol, Vol.76, No.3, (March 2005), pp. 323-8, ISSN 0022-3492

Cervelli, V. \& Gentile, P. (2009). Use of platelet gel in Romberg syndrome. Plast Reconstr Surg, Vol.123, No.1, (January 2009), pp. 22e-33e, ISSN 0032-1052

Chen, T.M., Tsai, J.C. \& Burnouf, T. (2010). A novel technique combining platelet gel, skin graft, and fibrin glue for healing recalcitrant lower extremity ulcers. Dermatol Surg, Vol.36, No.4, (April 2010), pp. 456-60, ISSN 1076-0512

Cieslik-Bielecka, A., Bielecki, T., Gazdzik, T.S., Cieslik, T., Szczepanski, T. (2008). Improved treatment of mandibular odontogenic cysts with platelet-rich gel. Oral Surg Oral Med Oral Pathol Oral Radiol Endod, Vol.105, No.4, (April 2008), pp. 423-9, ISSN 10792104

Council of Europe. (2011). Guide to the Preparation, Use and Quality Assurance of Blood Components (16 th Edition), Council of Europe, ISBN 978-92-871-7022-4, Strasbourg

Crovetti, G., Martinelli, G., Issi, M., Barone, M., Guizzardi, M., Campanati, B., Moroni, M. \& Carabelli, A. (2004). Platelet gel for healing cutaneous chronic wounds. Transfus Apher Sci, Vol.30, No.2, (April 2004), pp. 145-151, ISSN: 1473-0502

Dankert, J., van der W.J., Zaat, S.A., Joldersma, W., Klein, D. \& Hess, J. (1995). Involvement of bactericidal factors from thrombin-stimulated platelets in clearance of adherent viridans streptococci in experimental infective endocarditis. Infect Immun, Vol.63, No.2, (February 1995), pp.663-71, ISSN 0019-9567

Debus, E.S., Schmidt, K., Geiger, D., Dietz, U.A. \& Thiede A. (2001). Growth factors for preventing amputation in delayed wound healing. Kongressbd Dtsch Ges Chir Kongr, Vol.118, (2001), pp. 829-33, ISSN 1868-1050

Donald, T., (2011). Platelets take on new forms as sports medicine and wound-healing therapies. AABB News, Vol.13, No.3, (March 2011), pp. 18-23, ISSN 1523-939X 
De Somer, F., De Brauwer, V., Vandekerckhove. M., Ducatelle, R., Uyttendaele, D. \& Van Nooten, G. (2006). Can autologous thrombin with a rest fraction of ethanol be used safely for activation of concentrated autologous platelets applied on nerves? Eur Spine J, Vol.15, No.4, (April 2006), pp. 501-5, ISSN 0940-6719

Driver, V.R., Hanft, J., Fylling, C.P., Beriou, J.M. \& the Autologel Diabetic Foot Ulcer Study Group (2006). A prospective, randomized, controlled trial of autologous plateletrich plasma gel for the treatment of diabetic foot ulcers. Ostomy Wound Manage, Vol.52, No.6, (June 2006), pp. 68-70, 72, 74 passim, ISSN 0889-5899

Englert, S.J., Estep, T.H. \& Ellis-Stoll, C.C. (2008). Postoperative surgical chest and leg incision sites using platelet gel: a retrospective study. J Extra Corpor Technol, Vol.40, No.4, (December 2008), pp. 225-8, ISSN 0022-1058

Eppley, B.L., Pietrzak, W.S. \& Blanton, M. (2006). Platelet-rich plasma: a review of biology and applications in plastic surgery. Plast Reconstr Surg, Vol.118, No.6, (November 2006), pp. 147e-159e, ISSN 0032-1052

European Wound Management Association (EWMA). (2008). Position document: Hard-to-heal wounds: a holistic approach. MEP Ltd, London

Everts, P.A., Brown Mahoney, C., Hoffmann, J.J., Schonberger, J.P., Box, H.A., van Zundert, A. \& Knape, J.T. (2006a). Platelet-rich plasma preparation using three devices: implications for platelet activation and platelet growth factor release. Growth Factors, Vol.24, No.3, (September 2006), pp. 165-71, ISSN 0897-7194

Everts, P.A., Devilee, R.J., Brown Mahoney, C., Eeftinck-Schattenkerk, M., Box, H.A., Knape, J.T. \& van Zundert, A. (2006b). Platelet gel and fibrin sealant reduce allogeneic blood transfusions in total knee arthroplasty. Acta Anaesthesiol Scand, Vol.50, No.5, (May 2006), pp.593-9, ISSN 0001-5172

Everts, P.A., Hoffmann, J., Weibrich, G., Brown Mahoney, C., Schonberger, J.P., van Zundert, A. \& Knape, J.T. (2006c). Differences in platelet growth factor release and leucocyte kinetics during autologous platelet gel formation. Transfus Med, Vol.16, No.5, (October 2006), pp. 363-8, ISSN 0958-7578

Everts, P.A, Jakimowicz, J.J., van Beek, M., Schönberger, J.P., Devilee, R.J., Overdevest, E.P., Knape, J.T.A. \& van Zundert, A. (2007). Reviewing the structural features of autologous platelet-leukocyte gel and suggestions for use in surgery. Eur Surg Res, Vol.39, No.4, (April 2007), pp.199-207, ISSN 0014-312X

Everts, P.A., Devilee, R.J., Brown Mahoney, C., van Erp, A., Oosterbos, C.J., Stellenboom, M., Knape, J.T. \& van Zundert, A. (2008). Exogenous application of platelet-leukocyte gel during open subacromial decompression contributes to improved patient outcome. A prospective randomized double-blind study. Eur Surg Res, Vol.40, No.2, (November 2008), pp. 203-10, ISSN 0014-312X

Ficarelli, E., Bernuzzi, G., Tognetti, E., Bussolati, O., Zucchi, A., Adorni, D. \& De Panfilis, G. (2008).Treatment of chronic venous leg ulcers by platelet gel. Dermatol Ther, Vol.21, Issue Suppl. s1, (July/August 2008), pp. S13-7, ISSN 1396-0296

Fischer, H. (1979). A method of suture-free anastomosis of nerve transplantation is being reported, using facial nerve as the example. Laryngol Rhinol Otol, Vol.58, No.2 (February 1979), pp. 154-6, ISSN 0340-1588 
Fried, D.W., Leo, J.J., Weber, F.P., Husain, M. \& Cullen, J. (2006). Quantitative and qualitative analysis of platelet-rich plasma collection using the Haemonetics Cell Saver 5 in open heart surgery. J Extra Corpor Technol, Vol.38, No.3, (September 2006), pp. 235-40, ISSN 0022-1058

Fang, R.C. \& Galiano, R.D. (2008). A review of becaplermin gel in the treatment of diabetic neuropathic foot ulcers. Biologics. Vol.2, No.1, (March 2008), pp. 1-12,. ISSN 11775475

Frechette, J.P., Martineau, I. \& Gagnon, G. (2005). Platelet-rich plasmas: growth factor content and roles in wound healing. J Dent Res, Vol.84, No.5, (May 2005), pp. 434-9, ISSN 0022-0345

Garcia, A., Zitzmann, N. \& Watson, S.P. (2004). Analyzing the platelet proteome. Semin Thromb Hemost, Vol.30, No.4 (August 2004), pp.485-9, ISSN 0094-6176

Gardner, M.J., Demetrakopoulos, D., Klepchick, P.R. \& Mooar, P.A. (2007). The efficacy of autologous platelet gel in pain control and blood loss in total knee arthroplasty: An analysis of the haemoglobin, narcotic requirement and range of motion. Int Orthop, Vol.31, No.3, (June 2007), pp. 309-13, ISSN 0341-2695

Geuze, R.E., Wegman, F., Oner, F.C., Dhert, W.J. \& Alblas J. (2009). Influence of endothelial progenitor cells and platelet gel on tissue-engineered bone ectopically in goats. Tissue Eng Part A, Vol.15, No.11, (November 2009), pp. 3669-77, ISSN 1937-3341

Gilsanz, F., Escalante, F., Auray, C. \& Olbes, A.G. (2001). Treatment of leg ulcers in betathalassaemia intermedia: use of platelet-derived wound healing factors from the patient's own platelets. Br J Haematol, Vol.115, No.3, (December 2001), p.710, ISSN 0007-1048

Greiling, D. \& Clark, R.A. (1997). Fibronectin provides a conduit for fibroblast transmigration from collagenous stroma into fibrin clot provisional matrix. J Cell Sci, Vol.110, (April 1997), pp. 861-70, ISSN 0021-9533

Gresele, P., Page, C., Fuster, V. \& Vermylen, J. (Eds.). (2002). Platelets in Thrombotic and NonThrombotic Disorders: Patophysiology, Pharmacology and Therapeutics, Cambridge University Press, ISBN-13 978-0521802611, Cambridge

Gunaydin, S., McCusker, K., Sari, T., Onur, M., Gurpinar, A., Sevim ,H., Atasoy, P., Yorgancioglu, C. \& Zorlutuna, Y. (2008). Clinical impact and biomaterial evaluation of autologous platelet gel in cardiac surgery. Perfusion, Vol.23, No.3, (May 2008), pp. 179-86, ISSN 0267-6591

Harrison, P. \& Cramer, E.M. (1993). Platelet alpha-granules. Blood Rev, Vol.7, No.1, (March 1993), pp. 52-62, ISSN 0268-960X

Jünger, M., Steins, A., Hahn, M. \& Hafner, H.M. (2000). Microcirculatory dysfunction in chronic venous insufficiency (CVI). Microcirculation, Vol.7, No.S1, (December 2000), pp. S3-S12, ISSN 1073-9688

Jurk, K. \& Kehrel, B.E. (2005). Platelets: physiology and biochemistry. Semin Thromb Hemost, Vol.31, No.4, (2005), pp. 381-92, ISSN 0094-6176

Kantor, J. \& Margolis, D.J. (2000). The accuracy of using a wound care specialty clinic database to study diabetic neuropathic foot ulcers. Wound Repair Regen, Vol.8, No.3, (May-June 2000), pp. 169-73, ISSN 1067-1927 
Kark, L.R., Karp, J.M. \& Davies, J.E. (2006). Platelet releasate increases the proliferation and migration of bone marrow-derived cells cultured under osteogenic conditions. Clin Oral Implants Res, Vol.17, No.3, (June 2006), pp. 321-7, ISSN 0905-7161

Kevy, S.V. \& Jacobson, M.S. (2004). Comparison of methods for point of care preparation of autologous platelet gel. J Extra Corpor Technol, Vol.36, No.1, (March 2004), pp.28-35, ISSN 0022-1058

Knighton, D.R., Ciresi, K., Fiegel, V.D., Schumerth, S., Butler, E. \& Cerra F. (1990). Stimulation of repair in chronic, nonhealing, cutaneous ulcers using plateletderived wound healing formula. Surg Gynecol Obstet, Vol.170, No.1, (January 1990), pp. 56-60, ISSN 0039-6087

Kishimoto, T., Kikutani, H., von dem Borne, A.E.G.Kr., Goyert, S.M., Mason, D.Y., Miyasaka, M., Moretta, L., Okumura, K., Shaw, S., Springer, T.A., Sugamura, K. \& Zola, H. (Eds.). (1997). Leucocyte Typing VI: White Cell Differentiation Antigens, Garland Publishing, ISBN 0815327455, New York, NY

Koffler, B.H. (2006). Autologous serum therapy of the ocular surface with novel delivery by platelet concentrate gel. Ocul Surf, Vol.4, No.4, (October 2006), pp.188-95, ISSN 1542-0124

Kunicki, T.J. \& Nugent, D.J. (2006). Human platelet antigens, In: Blood banking and transfusion medicine, C.D. Hillyer, L.E. Silberstein, P.M. Ness \& K.N. Anderson, (Eds.), pp. 6380, W.B. Saunders Company, Philadelphia, PA ISBN 9780443065422,

Lacci, K.M. \& Dardik, A. (2010). Platelet-rich plasma: support for its use in wound healing. Yale J Biol Med., Vol.83, No.1, (March 2010), pp. 1-9, ISSN 0044-0086

Lacoste, E., Martineau, I. \& Gagnon, G. (2003). Platelet concentrates: effects of calcium and thrombin on endothelial cell proliferation and growth factor release. J Periodontol, Vol.74, No.10, (October 2003), pp.1498-507, ISSN 0022-3492

Lee, J.H. \& Kang, N.Y. (2011). Comparison of fibrin glue and sutures for conjunctival wound closure in strabismus surgery. Korean J Ophthalmol, Vol.25, No.3, (June 2011), pp.178-84, ISSN 1011-8942

Liu, L., Hartwig, D., Harloff, S., Herminghaus, P., Wedel, T., Kasper, K. \& Geerling, G. (2006). Corneal epitheliotrophic capacity of three different blood-derived preparations. Invest Ophthalmol Vis Sci, Vol.47, No.6, (June 2006), pp.2438-44, ISSN 0146-0404

Lundblad, R.L. \& White, G.C. (2005). The interaction of thrombin with blood platelets. Platelets, Vol.16, No.7, (November 2005), pp. 373-85, ISSN 0953-7104

Margolis, D.J., Kantor, J., Santanna, J., Strom, B.L. \& Berlin, J.A. (2001). Effectiveness of platelet releasate for the treatment of diabetic neuropathic foot ulcers. Diabetes Care, Vol.24, No.3, (March 2001), pp. 483-8, ISSN 0149-5992

Marx, R.E., Carlson, E.R., Eichstaedt, R.M., Schimmele, S.R., Strauss, J.E. \& Georgeff, K.R. (1998). Platelet-rich plasma: Growth factor enhancement for bone grafts. Oral Surg Oral Med Oral Pathol Oral Radiol Endod, Vol.85, No. 6, (June 1998), pp. 638-46, ISSN 1079-2104

Mazzucco, L., Cattana, E., Orecchia, S. \& Borzini, P. (2004). Enhancing of fibroblast proliferation by platelet extract. Vox Sang, Vol.87, Issue Suppl. s3 (2004), pp. S2-S16, ISSN 0042-9007 
Mazzucco, L., Balbo, V., Cattana, E. \& Borzini, P. (2008). Platelet-rich plasma and platelet gel preparation using Plateltex. Vox Sang, Vol.94, No.3, (April 2008), pp. 202-8, ISSN 0042-9007

Mazzucco, L., Balbo, V., Cattana, E., Guaschino, R. \& Borzini, P. (2009). Not every PRP-gel is born equal. Evaluation of growth factor availability for tissues through four PRPgel preparations: Fibrinet, RegenPRP-Kit, Plateltex and one manual procedure. Vox Sang, Vol.97, No.2, (August 2009), pp. 110-8, ISSN 0042-9007

McClain, S.A., Simon, M., Jones, E., Nandi, A., Gailit, J.O., Tonnesen, M.G., Newman, D. \& Clark, R.A., (1996). Mesenchymal cell activation is the rate-limiting step of granulation tissue induction. Am J Pathol, Vol.149, No.4, (October 1996), pp. 125770, ISSN 0002-9440

Mehta, S. \& Watson, J.T. (2008). Platelet rich concentrate: basic science and current clinical applications. J Orthop Trauma, Vol.22, No.6, (July 2008), pp. 432-8, ISSN 0890-5339

Mendez, R., Lopez-Cedrun, J.L., Patino, B., Vazquez, I., Martin-Sastre R., Tellado, M.G. \& Vela, D. (2006). Platelet-rich plasma (platelet gel) in secondary alveoloplasty in cleft patients. Cir Pediatr, Vol.19, No.1, (January 2006), pp. 23-6, ISSN 0214-1221

Metcalfe, P., Watkins, N.A., Ouwehand, W.H., Kaplan, C., Newman, P., Kekomaki, R., De Haas, M., Aster, R., Shibata, Y., Smith, J., Kiefel, V. \& Santoso S. (2003). Nomenclature of human platelet antigens. Vox Sang, Vol.85, No.3, (October 2003), pp. 240-5, ISSN 0042-9007

Millington, J.T. \& Norris, T.W. (2000). Effective treatment strategies for diabetic foot wounds. J Fam Pract, Vol.49, Suppl.11 (November 2000), pp. S40-S48, ISSN 00943509

Mogan, C. \& Larson, D.F. (2004). Rationale of platelets gel to augment adaptive remodelling of the injured heart. J Extra Corpor Technol, Vol.36, No.2, (June 2004), pp.191-6, ISSN 0022-1058

Naldini, A., Morena, E., Fimiani, M., Campoccia, G., Fossombroni, V. \& Carraro, F. (2008). The effects of autologous platelet gel on inflammatory cytokine response in human peripheral blood mononuclear cells. Platelets, Vol.19, No.4, (June 2008), pp. 268-74, ISSN 0953-7104

Novis, D.A., Renner, S., Friedberg, R.C., Walsh, M.K. \& Saladino, A.J. (2002). Quality indicators of fresh frozen plasma and platelet utilization. Arch Pathol Lab Med, Vol.126, No.5, (May 2002), pp. 527-32, ISSN 0003-9985

Palfreyman, S.S.J., Nelson, E.A., Lochiel, R. \& Michaels, J.A. (2006). Dressings for healing venous leg ulcers. Cochrane Database Syst Rev, Issue 3, (July 2006), Art. No. CD001103

Parazzi, V., Lazzari, L. \& Rebulla P. (2010). Platelet gel from cord blood: a novel tool for tissue engineering. Platelets, Vol.21, No.7, (2010), pp. 549-54, ISSN 0953-7104

Phillips, G.D., Stone, A.M., Whitehead, R.A. \& Knighton, D.R. (1994). Platelet derived wound healing factors (PDWHF) accelerate and augment wound healing angiogenesis in the rat. In Vivo, Vol.8, No.2, (March-April 1994), pp. 167-71, ISSN 0258-851X

Picardi, A., Lanti, A., Cudillo, L., Cerretti, R., Dentamaro, T., De Angelis, G., Ferraro, A., Di Veroli, A., Adorno, G. \& Arcese, W. (2010). Platelet gel for treatment of 
mucocutaneous lesions related to graft-versus-host disease after allogeneic hematopoietic stem cell transplant. Transfusion, Vol. 50, No.2, (February 2010), pp. 501-6, ISSN 0041-1132

Pomerantz, J. \& Dutton, J.M. (2005). Platelet gel for endoscopic sinus surgery. Ann Otol Rhinol Laryngol , 114, (2005), (699-704)

Powell, D.M., Chang, E. \& Farrior, E.H. (2001). Recovery from deep-plane rhytidectomy following unilateral wound treatment with autologous platelet gel: a pilot study. Arch Facial Plast Surg, Vol.3, No.4, (October-December 2001), pp. 245-50, ISSN 15212491

Rendu, F. \& Brohard-Bohn, B. (2001). The platelet release reaction: granules' constituents, secretion and functions. Platelets, Vol.21, No.5, (August 2001), pp. 261-73, ISSN 0953-7104

Reutter, H., Bort, S., Jung, M.F., Klyscz, T., Schippert, W., Zuder, D. \& Junger, M. (1999). Questionable effectiveness of autologous platelet growth factors (PDWHF) in treatment of venous ulcers of the leg. Hautarzt, Vol.50 ,No.12, (December 1999), pp. 859-65, ISSN 0017-8470

Rosenthal, A.R., Harbury, C., Egbert, P.R. \& Rubenstein, E. (1975). Use of a plateletfibrinogen-thrombin mixture as a corneal adhesive: experiments with sutureless lamellar keratoplasty in the rabbit. Invest Ophthalmol, Vol.14, No.11, (November 1975), pp. 872-5, ISSN 0020-9988

Rožman, P. (2002). Platelet antigens. The role of human platelet alloantigens (HPA) in blood transfusion and transplantation. Transpl Immunol, Vol.10, No.2-3, (August 2002), pp.165-181, ISSN 0966-3274

Rožman, P. \& Bolta, Z. (2007). Use of platelet growth factors in treating wounds and softtissue injuries. Acta Dermatovenerol Alp Panonica Adriat, Vol.16, No.4, (December 2007), pp. 156-65, ISSN 1318-4458

Rughetti, A., Giusti, I., D'Ascenzo, S., Leocata, P., Carta, G., Pavan, A., Dell'Orso, L. \& Dolo, V. (2008). Platelet gel-released supernatant modulates the angiogenic capability of human endothelial cells. Blood Transfus, Vol.6, No.1, (January 2008), pp. 12-7, ISSN 1723-2007

Salvadè, A., Della Mina, P., Gaddi, D., Gatto, F., Villa, A., Bigoni, M., Perseghin, P., Serafini, M., Zatti, G., Biondi, A. \& Biagi, E. (2010). Characterization of platelet lysate cultured mesenchymal stromal cells and their potential use in tissue-engineered osteogenic devices for the treatment of bone defects. Tissue Eng Part C Methods, Vol.16, No.2, (April 2010), pp.201-14, ISSN 1937-3384

Santoso, S. \& Kiefel, V. (1998). Human platelet-specific alloantigens: update. Vox Sang, Vol.74, Suppl.2, (1998), pp. 249-253, ISSN 0042-9007

Savarino, L., Cenni, E., Tarabusi, C., Dallari, D., Stagni, C., Cenacchi, A., Fornasari, P.M, Giunti, A. \& Baldini, N. (2006). Evaluation of bone healing enhancement by lyophilized bone grafts supplemented with platelet gel: a standardized methodology in patients with tibial osteotomy for genu varus. J Biomed Mater Res B Appl Biomater, Vol.76, No.2, (February 2006), pp. 364-72, ISSN 1552-4973

Sclafani, A.P., Romo, T., Ukrainsky, G., McCormick, S.A., Litner, J., Kevy, S.V. \& Jacobson, M.S. (2005). Modulation of wound response and soft tissue ingrowth in synthetic 
and allogeneic implants with platelet concentrate. Arch Facial Plast Surg, Vol.7, No.3, (May-June 2005), pp. 163-9, ISSN 1521-2491

Schallmoser, K., Bartmarm, C., Rohde, E., Reinisch, A., Kashofer, K., Emberger, W., Lanzer, G., Linkesch, W. \& Strunk, D. (2007). A novel system for highly efficient clinical scale propagation of human mesenchymal stem cells with human platelet lysate. Haematologica-the Hematology Journal, Vol. 92, Suppl.2, (2007), pp. 317-8, ISSN 03906078

Smrke, D., Gubina, B., Domanovic, D. \& Rozman, P. (2007). Allogeneic Platelet Gel with Autologous Cancellous Bone Graft for the Treatment of a Large Bone Defect. Eur Surg Res, Vol. 39, No.3, (March 2007), pp.170-4, ISSN 0014-312X

Stammers, A.H., Trowbridge, C.C., Marko, M., Woods, E.L., Brindisi, N., Pezzuto, J., Klayman, M., Fleming, S. \& Petzold, J. (2009). Autologous platelet gel: fad or savoir? Do we really know? J Extra Corpor Technol, Vol.41, No.4, (December 2009), pp. P25-30, ISSN 0022-1058

Steed, D.L., Goslen, J.B., Holloway, G.A., Malone, J.M., Bunt, T.J. \& Webster, M.W. (1992). Randomized prospective double-blind trial in healing chronic diabetic foot ulcers. CT-102 activated platelet supernatant, topical versus placebo. Diabetes Care, Vol.15, No.11, (November 1992), pp.1598-604, ISSN 0149-5992

Sun, B., Chen, B., Zhao, Y., Sun, W., Chen, K., Zhang, J., Wei, Z., Xiao, Z. \& Dai, J. (2009). Crosslinking heparin to collagen scaffolds for the delivery of human plateletderived growth factor. J Biomed Mater Res B Appl Biomater. Vol.91, No.1, (October 2009 ), pp. 366-72, ISSN 1552-4973

Sullivan, M.T., Cotten, R., Read, E.J. \& Wallace, E.L. (2007). Blood collection and transfusion in the United States in 2001. Transfusion, Vol.47, No.3, (March 2007), pp. 385-94, ISSN 0041-1132

Thompson, D.F., Letassy, N.A. \& Thompson, G.D. (1988). Fibrin glue: a review of its preparation, efficacy, and adverse effects as a topical haemostat. Drug intell clin pharm, Vol.22, No.12, (December 1988), pp. 946-52, ISSN 0012-6578

Trowbridge, C.C., Stammers, A.H., Wood, G.C., Murdock, J.D., Klayman, M., Yen, B.R., Woods, E. \& Gilbert, C. (2005). Improved outcomes during cardiac surgery: a multifactorial enhancement of cardiopulmonary bypass techniques. J Extra Corpor Technol, Vol.37, No.2, (June 2005), pp. 165-72, ISSN 0022-1058

Tschon, M., Fini, M., Giardino, R., Filardo, G., Dallari, D., Torricelli, P., Martini, L., Giavaresi, G., Kon, E., Maltarello, M.C., Nicolini, A. \& Carpi, A. (2011). Lights and shadows concerning platelet products for musculoskeletal regeneration. Front Biosci (Elite Ed), Vol.3, (January 2011), pp. 96-107, ISSN 1945-0494

Valencia, I.C., Falabella, A., Kirsner, R.S. \& Eaglstein, W.H. (2001). Chronic venous insufficiency and venous leg ulceration. J Am Acad Dermatol, Vol.44, No.3, (March 2001), pp. 401-21, ISSN 0190-9622

Weibrich, G., Kleis, W.K., Hafner, G. \& Hitzler, W.E. (2002). Growth factor levels in plateletrich plasma and correlations with donor age, sex, and platelet count. J Craniomaxillofac Surg, Vol.30, No.2, (April 2002), pp. 97-102, ISSN 1010-5182 
Westerhuis, R.J., van Bezooijen, R.L. \& Kloen, P. (2005). Use of bone morphogenetic proteins in traumatology. Injury, Vol.36, No.12, (December 2005), pp. 1405-12, ISSN 00201383

Whitman, D.H., Berry, R.L. \& Green, D.M. (1997). Platelet gel: an autologous alternative to fibrin glue with applications in oral and maxillofacial surgery. J Oral Maxillofac Surg, Vol.55, No.11, (November 1997), pp. 1294-9, ISSN 0278-2391

Zhang, J.,Blackmore, P.F., Hargrave, B.Y., Xiao, S., Beebe, S.J. \& Schoenbach, K.H. (2008). Nanosecond pulse electric field (nanopulse): a novel non-ligand agonist for platelet activation. Arch Biochem Biophys, Vol.471, No.2, (March 2008), pp. 240-8, ISSN 00039861

Zimmermann, R., Arnold, D., Strasser, E., Ringwald, J., Schlegel, A., Wiltfang, J. \& Eckstein, R. (2003). Sample preparation technique and white cell content influence the detectable levels of growth factors in platelet concentrates. Vox Sang, Vol.85, No.4 (2003), pp. 283-9, ISSN 0042-9007 


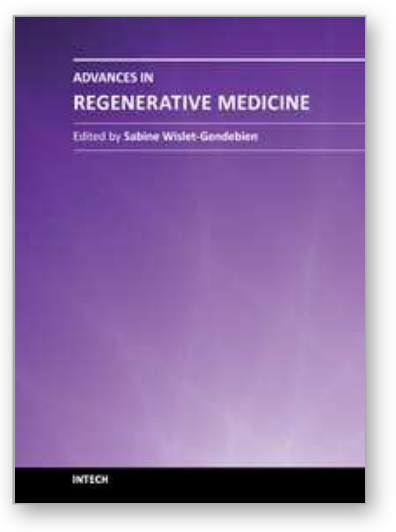

\author{
Advances in Regenerative Medicine \\ Edited by Dr Sabine Wislet-Gendebien
}

ISBN 978-953-307-732-1

Hard cover, 404 pages

Publisher InTech

Published online 21, November, 2011

Published in print edition November, 2011

Even if the origins of regenerative medicine can be found in Greek mythology, as attested by the story of Prometheus, the Greek god whose immortal liver was feasted on day after day by Zeus' eagle; many challenges persist in order to successfully regenerate lost cells, tissues or organs and rebuild all connections and functions. In this book, we will cover a few aspects of regenerative medicine highlighting major advances and remaining challenges in cellular therapy and tissue/organ engineering.

\title{
How to reference
}

In order to correctly reference this scholarly work, feel free to copy and paste the following:

Primož Rožman, Danijela Semenič and Dragica Maja Smrke (2011). The Role of Platelet Gel in Regenerative Medicine, Advances in Regenerative Medicine, Dr Sabine Wislet-Gendebien (Ed.), ISBN: 978-953-307-732-1, InTech, Available from: http://www.intechopen.com/books/advances-in-regenerative-medicine/the-role-ofplatelet-gel-in-regenerative-medicine

\section{INTECH}

open science | open minds

\section{InTech Europe}

University Campus STeP Ri

Slavka Krautzeka 83/A

51000 Rijeka, Croatia

Phone: +385 (51) 770447

Fax: +385 (51) 686166

www.intechopen.com

\section{InTech China}

Unit 405, Office Block, Hotel Equatorial Shanghai

No.65, Yan An Road (West), Shanghai, 200040, China 中国上海市延安西路65号上海国际贵都大饭店办公楼 405 单元

Phone: +86-21-62489820

Fax: +86-21-62489821 
(C) 2011 The Author(s). Licensee IntechOpen. This is an open access article distributed under the terms of the Creative Commons Attribution 3.0 License, which permits unrestricted use, distribution, and reproduction in any medium, provided the original work is properly cited. 